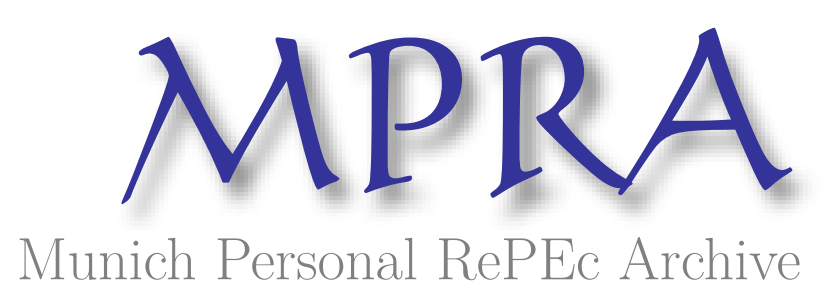

\title{
Default Risk and Risk Averse International Investors
}

Lizarazo, Sandra

24 January 2010

Online at https://mpra.ub.uni-muenchen.de/20794/

MPRA Paper No. 20794, posted 20 Feb 2010 16:45 UTC 


\title{
Default Risk and Risk Averse International Investors
}

\author{
Sandra Valentina Lizarazo ${ }^{\dagger}$
}

First draft: March, 2005

This draft: January, 2010

\begin{abstract}
This paper develops a model of debt and default for small open economies that interact with risk averse international investors. The model developed here extends the recent work on the analysis of endogenous default risk to the case in which international investors are risk averse agents with decreasing absolute risk aversion (DARA). By incorporating risk averse investors who trade with a single emerging economy, the present model offers two main improvements over the standard case of risk neutral investors: i.) the model exhibits a better fit of debt-to-output ratio and ii.) the model explains a larger proportion and volatility of the spread between sovereign bonds and riskless assets. The paper shows that if investors have DARA preferences, then the emerging economy's default risk, capital flows, bond prices and consumption are a function not only of the fundamentals of the economy - as in the case of risk neutral investors - but also of the level of financial wealth and risk aversion of the international investors. In particular, as investors become wealthier or less risk averse, the emerging economy becomes less credit constrained. As a result, the emerging economy's default risk is lower, and its bond prices and capital inflows are higher. Additionally, with risk averse investors, the risk premium in the asset prices of the sovereign countries can be decomposed into two components: a base premium that compensates the investors for the probability of default (as in the risk neutral case) and an "excess" premium that compensates them for taking the risk of default.
\end{abstract}

\footnotetext{
${ }^{\dagger}$ Centro de Investigación Economica, ITAM, Mexico, D.F. Email: slizarazo@itam.mx I would like to thank to Árpád Ábrahám, Martin Uribe, Stephanie Schmitt-Grohé, and Albert 'Pete' Kyle for their advice. All remaining errors are my own.
} 


\section{Introduction}

This paper extends the recent work in endogenous default risk to the case in which international investors are risk averse agents whose preferences exhibit decreasing absolute risk aversion (DARA). The current paper develops a model of debt and default for a small open economy that interacts with risk averse international investors. This model is used to account for nine stylized facts regarding emerging financial markets:

(i) Emerging economies experience a loss of access to international capital markets and large reversals of their current account deficits in times of crises. ${ }^{1}$

(ii) Emerging economies' domestic interest rates are counter-cyclical. ${ }^{2}$

(iii) Default on sovereign debts occurs in equilibrium. ${ }^{3}$

(iv) Emerging economies' credit ratings are negatively correlated with their income level and their growth rate, and positively correlated with the size of their external debt. ${ }^{4}$

(v) Emerging economies' estimated default probabilities do not account for all of the yield spreads in their sovereign bonds. ${ }^{5}$

(vi) The proportion of sovereign yield spreads explained by emerging economies' own fundamentals is smaller for riskier sovereign bonds than for investment grade bonds. ${ }^{6}$

(vii) Investors' financial performance and their net foreign asset position in emerging economies are positively correlated. ${ }^{7}$

(viii) Emerging economies' credit spreads are positively correlated with spreads of corporate junk bonds from developed countries. ${ }^{8}$

\footnotetext{
${ }^{1}$ The literature on "sudden-stops" has focused on explaining the dynamics of the loss of access to international capital markets that emerging economies experience during periods of crises.

${ }^{2}$ Uribe and Yue (2006) and Neumeyer and Perri (2005) focus on the counter-cyclical behavior of domestic interest rate for emerging markets.

${ }^{3}$ Kaminsky and Reinhart (1998) and Reinhart et al. (2003) document and empirically analyze default events.

${ }^{4}$ Cantor and Pecker (1996) analyzes the determinants of credit ratings.

${ }^{5}$ Westphalen (2001) and Broner et al.(2005) have considered bond spreads and the role of the probability of default in the determination of such spreads.

${ }^{6}$ See, for example, Cantor and Pecker (1996), Cunningham et al.(2001), Westphalen (2001), and Kamin and von Kleist (1999).

${ }^{7}$ See for example Goldberg (2001), Hernandez et al.(2001), FitzGerald and Krolzig (2003), and Mody and Taylor (2003).

${ }^{8}$ See, for example, FitzGerald and Krolzig (2003), Ferruci et al.(2004), and Mody and Taylor (2004).
} 
(ix) Sovereign bond spreads across emerging economies are highly correlated. ${ }^{9}$

In the model presented here, three types of agents interact through international financial emerging markets: developed economies' agents, emerging economies' agents, and international financial intermediaries. Financial intermediaries or investors take the form of mutual funds, hedge funds, pension funds, etc. These agents invest in emerging financial markets in the name of developed economies' agents - i.e. developed economies' agents are able to invest in emerging market assets by holding shares of mutual funds, pensions or hedge funds. Since intermediaries act in tandem with developed economies' agents, these two actors will not be modeled separately. Therefore only two types agents will be explicitly modeled, the agents of the emerging economies and international investors.

It is assumed that all of the agents of the emerging economy are identical, all the international investors are identical, and that none of these agents follow mixed strategies. Under these assumptions, it is possible to focus on the representative agent of each type. For her part, the representative investor is a risk averse agent. This agent solves a dynamic portfolio problem in which she decides the optimal allocation of her portfolio between bonds of the emerging economy and riskless assets denominated as T-Bills. On the other side of the market, the representative agent of the emerging economy is also a risk averse agent who solves a dynamic optimization problem. Each period, this agent receives an stochastic endowment and chooses her consumption and savings subject to her budget constraint. The emerging economy borrows or saves by trading one-period non-contingent bonds with the representative investor. The interaction between the two parties determines the equilibrium price of the bonds in the emerging economy.

On the side of the emerging economy, there is limited liability. While the representative investor is able to commit to repay any debt that she might have, the representative agent of the emerging economy is not. In this case, the emerging economy might default on her debts. If she defaults, she is excluded from international credit markets temporarily.

Because of the enforcement problem the price of the bonds of the economy depends on the likelihood of repayment of the debt. This likelihood of repayment by the economy depends on the borrowing of the economy. Both the representative investor, and the representative agent of the economy take as given the price function of the emerging economy's non-contingent discount bonds, $q$.

\footnotetext{
${ }^{9}$ See, for example, Valdes (1996), Baig and Goldfajn (1998), Baig and Goldfajn (2000), and Forbes and Rigobon (1999).
} 
As laid out here, the asset market is imperfect in three different ways. First, there is a one-sided commitment problem which implies that debt contracts with the emerging economy are not enforceable. Second, markets are incomplete because the only traded assets are one period no-contingent bonds, and risk free T-Bills. Therefore the representative investor is not able to insure away the income uncertainty specific to the emerging country. Third, the market structure of the financial market is non-competitive: investors form a cartel that colludes to punish any deviant borrower through the exclusion from international credit markets.

By relaxing the assumption of risk neutrality, and allowing for wealth effects on the side of the international investors, the model presented here attempts to better match the facts of international financial markets during the last two decades of the 20th century. These facts are only partially explained in the existing sovereign debt literature. Under the assumption that investors are risk neutral, previous models of endogenous sovereign risk have explained stylized facts (i) through (iv). ${ }^{10}$ As a result of incorporating risk averse investors with DARA preferences, the model presented here endogenously explains all of the stylized facts listed above.

The present model explains stylized facts (v) through (ix) as follows. First, international investors demand an excess risk premium in order to willingly take the risk of default embodied in the emerging economies' sovereign bonds (i.e. a risk averse agent would only take a risk that is actuarially favorable.). Therefore the present model is able to account for stylized fact (v): the price of the emerging economy's bonds is lower than the world price of riskless bonds adjusted by the emerging economy's default probability. This result is consistent with the findings of the empirical finance literature on sovereign bond spreads. Those findings suggest that under the assumption of risk neutral investors and competitive financial markets, the price of sovereign bonds cannot be completely explained by the estimated probabilities of default. ${ }^{11}$

Second, as risk averse agents, international investors demand a higher risk premium for higher levels of risk - above the premium predicted solely by the probability of default.

\footnotetext{
${ }^{10}$ This literature begins with Eaton and Gersovitz (1981). More recent examples include Aguiar and Gopinath (2006), Yue(2006), Bai and Zhang (2006), Arellano (2008), Hatchondo, Martinez and Sapriza (2008) and Cuadra and Sapriza(2008).

${ }^{11}$ An alternative explanation exists which does not depend on risk aversion. Sovereign bonds could be mispriced under the assumption that international investors do not take prices as given. However this assumption only explains stylized fact (v). Stylized facts (vi) through (ix) cannot be accounted for by a model in which portfolio allocations to each emerging country are independent of the wealth of the investors and the overall risk of the portfolio.
} 
With risk averse investors, the risk premium can be decomposed in two components: a base premium that compensates the investors for the probability of default and an "excess" premium that compensates them for taking the risk of default. ${ }^{12}$ Therefore the present model is able to account for stylized fact (vi): The proportion of sovereign yield spreads explained by default probabilities is smaller for riskier sovereign bonds than for less risky bonds. This result is consistent with the empirical regularity reported in several papers: that spreads in investment grade bonds can be explained to a larger extent by emerging economies' fundamentals than spreads in speculative grade bonds.

Third, since investors' preferences exhibit DARA, these agents are able to tolerate more default risk the wealthier they are. Therefore the present model can account for stylized fact (vii): there is a positive correlation between the representative lender's wealth and the lender's investment in the emerging economy. This result is consistent with empirical findings which demonstrate a positive relation between proxies of investors wealth (like developed economies' output or stock indexes) and capital flows to emerging economies.

Fourth, the endogenous credit limits faced by the emerging economy become increasingly tight when the lender's risk aversion increases. This tightening occurs because a more risk averse investor demands a higher risk premium in order to accept default risk. Therefore, for any given level of risk aversion of the representative investor, the set of financial contracts available to the emerging economy is always a subset of the set of contracts available to an identical economy trading with a less risk averse lender. ${ }^{13}$ This result is consistent with stylized fact (viii): whenever investors' willingness to take risk changes, there must be a change in the spreads of all risky assets. As a consequence, the spreads of emerging economies' sovereign bonds and the spreads of industrialized economies' junk bonds should exhibit some co-movement.

Fifth, under DARA preferences, investors have a higher tolerance for risk when they are wealthier. Therefore at higher levels of wealth, these agents demand a smaller risk premium than at lower levels of wealth in order to take the same amount of default risk. Furthermore, a smaller risk premium in the emerging economy's bonds increases the benefits to the economy of fulfilling its contract. Since these effects reinforce each other, the equilibrium price of sovereign bonds is an increasing function of investors' wealth levels. This result is consistent with the empirical literature on the determination of sovereign credit spreads

\footnotetext{
${ }^{12}$ Models with risk neutral investors only capture the base premium.

${ }^{13} \mathrm{~A}$ financial contract in this context is the combination of the bond prices and quantities that the emerging economy can borrow or save.
} 
for emerging economies, ${ }^{14}$ and implies that the current model can explain stylized fact (ix): sovereign bond spreads across emerging economies are highly correlated because the equilibrium price of the emerging economy's bonds varies with the representative investor's wealth..$^{15}$

The assumption of DARA preferences on the side of the investors seems to be justified by the characteristics of the players in emerging financial markets. These players are both individuals and institutional investors such as banks, mutual funds, hedge funds, pension funds and insurance companies. For the case of individual investors, it is straightforward to assume that these agents are risk averse. They can be treated as the representative agent of developed economies; it is standard practice in the literature to treat these agents as risk averse. In the case of institutional investors the assumption of risk aversion is somewhat more difficult, but nevertheless quite plausible. For these investors, risk aversion may follow from two sources: regulations over the composition of their portfolio and the characteristics of the institutions' management. Regarding the first source, banks face capital adequacy ratios; mutual funds face restrictions in their access to leverage against their asset holdings; and pension funds and insurance companies face strict limits on their exposure to risk. Regarding the second source, for each class of institutional investor, managers ultimately make the portfolio allocation decisions. These managers can also be treated as representative agents of developed economies. Additionally, the remuneration - and therefore the wealthof these agents is closely related to the performance of the portfolio that they manage. These factors suggest that portfolio choices of institutional investors will be consistent with the choices of agents whose preferences exhibit DARA.

This paper is organized as follows: section 1 is the introduction; section 2 presents the theoretical model; section 3 characterizes the equilibrium of the model; section 4 discusses the quantitative implications of the model; and section 5 concludes. Two appendixes provide proofs of propositions presented in the main text and the algorithm that solves the model.

\footnotetext{
${ }^{14}$ For example, Warther (1995), Ferruci et al.(2004), FitzGerald and Krolzig (2003), and Westphalen (2001).

${ }^{15}$ This result of the model is consistent with the literature on financial contagion. A large body of empirical literature presents evidence that financial links play a significant role in explaining simultaneous financial crises and correlated spreads across emerging economies. See, for example, Kaminsky and Reinhart (1998), Kaminsky and Reinhart (2000), Van Rijckeghem and Weder (2001), Kaminsky et al.(2001), and Hernández and Valdes (2001).
} 


\section{THE MODEL}

The model is a discrete time, infinite horizon model. There are two types of agents in the model, a representative agent small open economy, and a representative risk averse international investor. In each period, the emerging economy receives a stochastic endowment of tradable goods. The representative agent of this economy may smooth her consumption across periods by trading non-contingent discount bonds with the representative investor. For her part, the representative investor may trade assets with the emerging country or with industrialized countries. Thus the investor must choose an optimal allocation of her portfolio between the bonds of the emerging economy and bonds of the industrialized countries, denominated hereafter as T-Bills.

The market for T-bills, $\theta^{T B}$, will not be modeled explicitly. Since debt contracts between the representative investor and industrialized countries are assumed to be enforceable, the representative investor is a price taker in the market for T-Bills. The price of T-Bills, $q^{f}$, which is not determined endogenously in this context, is assumed to be deterministic. Therefore T-Bills are riskless assets.

Bonds of emerging economies, $b$, on the other hand, are risky assets because debt contracts between the representative investor and the emerging economy are not enforceable. As a consequence, there is a one sided commitment problem. While the representative investor is able to commit to honor her debt obligations with the emerging economy, the representative agent of the emerging country is not able to commit to honor her obligations with international investors. Therefore, in each period, the representative agent of the emerging economy compares the costs and benefits derived from the repayment of her obligations. The decision between repayment or default is made individually by each agent of the emerging economy. Each agent of this economy makes her decision, taking as given the decision of the other agents. However given that all agents are identical who do not follow mixed strategies, it is possible to focus attention on the problem of the representative agent.

If the economy defaults, international investors are able to collude to punish her. As a consequence of default, it is assumed that investors will collude to exclude the defaulting country for a random number of periods from the financial markets. Since all investors behave in the same exact way, it is possible to focus on the representative international investor.

Both, the representative investor and the representative agent of the economy take as given the price function of the emerging economy's non-contingent discount bonds, $q$. 


\subsection{International investors}

There are a large but finite number of price-taking identical investors. Investors collude in order to punish any borrower that defaults on her debts, so that a defaulting country is temporarily excluded from the financial markets. ${ }^{16}$

The representative investor is a risk averse agent whose preferences over consumption are defined by a constant relative risk aversion (CRRA) periodic utility function with parameter $\gamma^{L}>0$. The investor has perfect information regarding the income process of the emerging economy, and in each period the investor is able to observe the realizations of this endowment.

The representative investor maximizes her discounted expected lifetime utility from consumption

$$
\underset{c_{t}^{L}}{\operatorname{Max}} E_{0} \sum_{t=0}^{\infty} \beta_{L}^{t} v\left(c_{t}^{L}\right)
$$

where $c^{L}$ is the investor's consumption. The periodic utility of this agent is given by $v\left(c^{L}\right)=\frac{\left(c^{L}\right)^{1-\gamma^{L}}}{1-\gamma^{L}}$. The representative investor is endowed with some initial wealth, $W_{0}$, at time 0 , and in each period, the investor receives an exogenous income $X$.

Because the representative investor is able to commit to honor her debt, she can borrow or lend from industrialized countries (which are not explicitly modeled here) by buying T-Bills at the deterministic risk free world price of $q^{f}$. The representative investor can also invest in non-contingent bonds of the emerging economy. These bonds have an endogenously determined stochastic price of $q$. In each period, the representative investor faces the budget constraint

$$
W+X=c^{L}+d q \theta^{\prime}+q^{f} \theta^{T B \prime}
$$

where $W$ is investors wealth at time $t, \theta^{\prime}$ is the portfolio allocation to the emerging country and $\theta^{T B^{\prime}}$ is the investor's allocation to the riskless asset. $d$ is an indicator variable that determines the default/repayment state of the emerging economy in the current period. $d$ takes the value of 1 if both the economy is not under the punishment of exclusion from financial markets as a result of a default in a previous period and the economy chooses to repay its debts, and takes a value of 0 otherwise.

It is assumed that investors cannot go short in their investments with emerging

\footnotetext{
${ }^{16}$ Empirical evidence suggest that once a country defaults, that country is excluded from the credit market for an average of 5.4 years (see Gelos, et al. (2004)).
} 
economies. Therefore whenever the emerging economy is saving, the representative international investor receives these savings and invests them completely in T-Bills. The representative investor does not use these resources to go long in T-Bills. This assumption implies that $\theta^{\prime} \geq 0$ for all $t .{ }^{17}$

The law of motion of the representative investor's wealth is given by

$$
W^{\prime}=d^{\prime} \theta^{\prime}+\theta^{T B \prime}
$$

The optimization problem that the representative investor faces can be described as one in which in each period, $t$, the representative international investor optimally chooses her portfolio according to her preferences in order to maximize her discounted expected lifetime utility from consumption, subject to her budget constraint, the law of motion of her wealth, and given $W_{0}$. This dynamic problem can be represented recursively by the Bellman Equation

$$
\begin{aligned}
V^{L}(s)=\max _{\theta^{\prime}, \theta^{T B \prime}} & v\left(c^{L}\right)+E \beta_{L} V\left(s^{\prime}\right) \\
\text { s.t. } \quad W+X & =c^{L}+d q \theta^{\prime}+q^{f} \theta^{T B^{\prime}} \\
W^{\prime} & =d^{\prime} \theta^{\prime}+\theta^{T B^{\prime}} \\
\theta^{\prime} & \geq 0 \\
c^{L} & >0 \\
W^{\prime} & \geq \underline{\underline{W}}
\end{aligned}
$$

where $s$ is defined as follows:

Definition 1 The state of the world, s, is given by the realization of the emerging economy's endowment, $y$, the emerging economy's asset position, $b$, the representative investor's asset position or wealth, $W$, and the variable $d$ which states whether or not the emerging economy is in default.

\footnotetext{
${ }^{17}$ This assumption does not seem to be inconsistent with reality. For example, mutual funds are strictly restricted by The Investment Company Act in their ability to leverage or borrow against the value of securities in their portfolio. On the other hand, hedge funds and other types of investors face no such restrictions. Because of these regulations it seems reasonable to make the simplifying assumption that international investors are able to leverage the riskless asset, $\theta^{T B}$, but must have a non-negative position in the emerging economy's asset.
} 
Equation (5) corresponds to the "natural" debt limit discussed in Aiyagari (1994), which prevents the representative investor from running ponzi games.

Given the assumption that the representative investor is not credit constrained (Equation (5)) the solution to the stochastic dynamic problem for the representative investor can be characterized by the following Kunh-Tucker conditions:

For $\theta^{T B \prime}$

$$
q^{f} v_{c^{L}}\left(c^{L}\right)=\beta_{L} E\left[v_{c^{L}}\left(c^{L^{\prime}}\right)\right]+\left(\beta^{L} E\left[\varpi^{\prime}\right]-q^{f} \varpi\right)
$$

For $\theta_{j}^{\prime}$

$$
q\left(v_{c^{L}}\left(c^{L}\right)+\varpi\right) d=\beta_{L} E\left[\left(v_{c^{L}}\left(c^{L^{\prime}}\right)+\varpi^{\prime}\right) d^{\prime}\right] d .
$$

where $\varpi$ corresponds to the multiplier on the non-negativity constraint for the investors consumption $c^{L}$.

For $X$ sufficiently large the non-negativity constraints for the representative investor's consumption are not binding at any time (therefore $\varpi=\varpi^{\prime}=0$ ). In such case the investor's optimization problem has an interior solution for the portfolio allocation. In what follows the focus would be on the case in which the solution for the investor's optimization problem is interior. In the next sub-section the case of a non interior solution for the investor's problem is discussed briefly.

When the non-negativity constraints are not binding the Kuhn-Tucker conditions for the investor's problem correspond to the following first order conditions:

$$
q^{f} v_{c^{L}}\left(c^{L}\right)=\beta_{L} E\left[v_{c^{L}}\left(c^{L^{\prime}}\right)\right] .
$$

For $\theta_{j}^{\prime}$

$$
q v_{c^{L}}\left(c^{L}\right) d=\beta_{L} E\left[v_{c^{L}}\left(c^{L^{\prime}}\right) d^{\prime}\right] d
$$

According to Equation (8), the investor chooses an allocation to the riskless asset such that the discounted expected marginal benefit of future consumption equals the marginal cost of current consumption. Equation (9) determines the allocation of the investor's resources to the emerging country. Unless the emerging country is not in default state, i.e. $d=1$, the emerging country does not belong in the investment set of the international investors. If the country is not in default state, then Equation (9) also equates the marginal cost of allocating wealth to bonds issued by the emerging country to the discounted expected marginal benefit of this investment. The benefit of this investment is realized only in those periods in which the emerging economy optimally chooses to repay its debts $\left(d^{\prime}=1\right)$. 
For the case in which $d=1$, equation (9) highlights the fact that the endogenous risk of default by the emerging economy - i.e. the case for which $d^{\prime}=0$ for some state of the world in the next period - will reduce the representative investor's expected marginal benefit of investing in the emerging economy. Everything else equal, this result will tend to reduce the allocation of resources to the emerging economy relative to the case where the emerging economy could commit to repayment.

To understand the role that the investor's risk aversion plays in this model, it is instructive to analyze in detail the determination of the equilibrium price of the emerging economy's bonds. It is possible to manipulate equation (9) to get

$$
\begin{aligned}
q & =\frac{\beta_{L} E\left[v_{c^{L}}\left(c^{L^{\prime}}\right) d^{\prime}\right]}{v_{c^{L}}\left(c^{L}\right)} \\
& =\beta_{L} \frac{\operatorname{Cov}\left[v_{c^{L}}\left(c^{L^{\prime}}\right) d^{\prime}\right]+E v_{c^{L}}\left(c^{L^{\prime}}\right) E d^{\prime}}{v_{c^{L}}\left(c^{L}\right)} \\
& =\frac{\beta_{L} \operatorname{Cov}\left[v_{c^{L}}\left(c^{L^{\prime}}\right) d^{\prime}\right]}{v_{c^{L}}\left(c^{L}\right)}+q^{f}(1-\delta) \\
& =\frac{\beta_{L} \operatorname{Cov}\left[v_{c^{L}}\left(c^{L^{\prime}}\right) d^{\prime}\right]}{v_{c^{L}}\left(c^{L}\right)}+q^{R N} . \\
& =\zeta^{R A}+q^{R N} .
\end{aligned}
$$

Where $E d^{\prime}=1-\delta$, and $\delta$ is the probability that the emerging economy will default in the next period.

Equation (10) shows that the bond prices of economies that trade financially with risk averse investors can be decomposed in two different components. The first component $q^{R N}$ corresponds to the price of the emerging economy's bonds that would equate the expected earnings of investing in the economy's risky bonds to the earnings obtained by investing in riskless bonds. Given emerging economy's default decisions for next period $d^{\prime}$, this price would prevail in a world with a risk neutral investor.

$$
q^{R N}=q^{f}(1-\delta)
$$

The second component of the emerging economy's bond prices $\zeta^{R A}$ corresponds to an "excess" risk premium that sovereign bonds have to carry in order to induce risk averse investors to hold them. This term is the principal source of the differences in the results of this model, and the model of endogenous sovereign risk and risk neutral investors. 
The main determinant of the "excess" risk premium $\zeta^{R A}$ is the covariance term in equation (10). When the emerging economy does not find it optimal to default at $t+1$ in any state of the world, then $d^{\prime}=1$ for all states. Therefore $\operatorname{Cov}\left[v_{c^{L}}\left(c^{L^{\prime}}\right) d^{\prime}\right]=0$. On the other hand, in the case when the emerging economy finds optimal to default at $t+1$ in all states of the world, then $d^{\prime}=0$ for all states. Also in this case $\operatorname{Cov}\left[v_{c^{L}}\left(c^{L^{\prime}}\right) d^{\prime}\right]=0$. But when at $t+1$ there exist some states of the world in which the emerging economy would optimally choose to default, then for the states in which it is not optimal to default, $d^{\prime}=1$. In this case, the wealth of the representative investor at $t+1$ is given by

$$
\left[W^{\prime} \mid\left(d^{\prime}=1\right)\right]=\theta^{\prime}+\theta^{T B \prime}
$$

and the wealth of the representative investor at $t+1$ for the states in which the emerging economy finds it optimal to default $\left(d^{\prime}=0\right)$ is given by

$$
\left[W^{\prime} \mid\left(d^{\prime}=0\right)\right]=\theta^{T B^{\prime}}
$$

It is obvious that

$$
\left[W^{\prime} \mid\left(d^{\prime}=1\right)\right]>\left[W^{\prime} \mid\left(d^{\prime}=0\right)\right] .
$$

Therefore it must hold that

$$
\left[c^{L^{\prime}} \mid\left(d^{\prime}=1\right)\right] \geq\left[c^{L^{\prime}} \mid\left(d^{\prime}=0\right)\right]
$$

and by concavity of the investor's utility function

$$
\left[v_{c^{L}}\left(c^{L^{\prime}}\right) \mid\left(d^{\prime}=1\right)\right] \leq\left[v_{c^{L}}\left(c^{L^{\prime}}\right) \mid\left(d^{\prime}=0\right)\right] .
$$

As a consequence, for higher $d^{\prime}$, we have lower $v_{c^{L}}\left(c^{L^{\prime}}\right)$. Clearly for this case

$$
\operatorname{Cov}\left[v_{c^{L}}\left(c^{L^{\prime}}\right) d^{\prime}\right]<0 .
$$

Therefore this covariance term is non-positive:

$$
\operatorname{Cov}\left[v_{c^{L}}\left(c^{L^{\prime}}\right) d^{\prime}\right] \leq 0 .
$$

Given the fact that the covariance term is non-positive the emerging economy's bond prices in this model are lower than the prices that would be observed in a model with risk neutral investors even in the case in which the probabilities of default were identical in both models.

It is worth examining how the covariance term is affected by four of the relevant variables in the model: the level of risk aversion of the investor, the investor's wealth, the investor's 
exposure to the emerging economy's debt, and the riskiness of the emerging economy's assets.

First, in looking at the investor's risk aversion, basic asset pricing theory implies that the more risky an asset looks in the eyes of the investor, the larger should be its "excess" risk premium $\zeta^{R A}$. Clearly, from an investor's perspective, an asset would seem more risky the less tolerant of risk is this investor. As a consequence, the covariance term is larger for higher levels of investors' risk aversion, $\gamma^{L}$, or for lower levels of investors' wealth, $W$ : the concavity of the investor's utility function implies that whenever $\gamma^{L}$ is high or when $W$ is low, the investor's marginal utility of consumption, $v_{c^{L}}\left(c^{L^{\prime}}\right)$, responds much more to changes in the investor's consumption, $c^{L}$, that are generated by the realized earnings/losses of the investments in the emerging economy.

Second, in looking at the investor's wealth, Figure 1 illustrates the behavior of the covariance term as a function of the investor's wealth keeping fixed the asset position of the emerging economy, the economy's endowment realization, and the investor's degree of risk aversion. We see in this figure that the covariance term is more negative the lower is investor's wealth. Therefore the "excess" risk premium is larger for low levels of investor's wealth. For example, for the case simulated numerically in this paper, when the economy has the lowest possible realization of income -an income that is $20 \%$ below trend-, and her debt level corresponds to $20.5 \%$ of her average income, we observe that whenever the investor's wealth corresponds to nearly 3.5 times the average income of the emerging economy, the "excess" risk premium is $15 \%$; when the investor's wealth is 0 the "excess" risk premium increases to almost $40 \%$.

Third, in looking at the investor's exposure to the emerging economy's debt, increasing exposure should increase the "excess" risk premium - even if the intrinsic riskiness of the economy's assets could be kept fixed when the level of debt of the economy increases. The obvious explanation for this result is that even with a fixed default probability for the economy, a larger exposure to the economy's debt would increase the riskiness of the investor's portfolio, and therefore should command a larger "excess" risk premium.

Figure 2 shows the behavior of the covariance term as function of the economy's debt level holding constant the endowment of the economy, and the investor's wealth and degree of risk aversion. The probability of default is not held constant; therefore we observe a non-monotonic behavior of the covariance term and the "excess" risk premium.

For high levels of debt, as a consequence of very high default probabilities bond prices are zero or very close to zero. For these levels of debt the role of the "excess" risk premium 

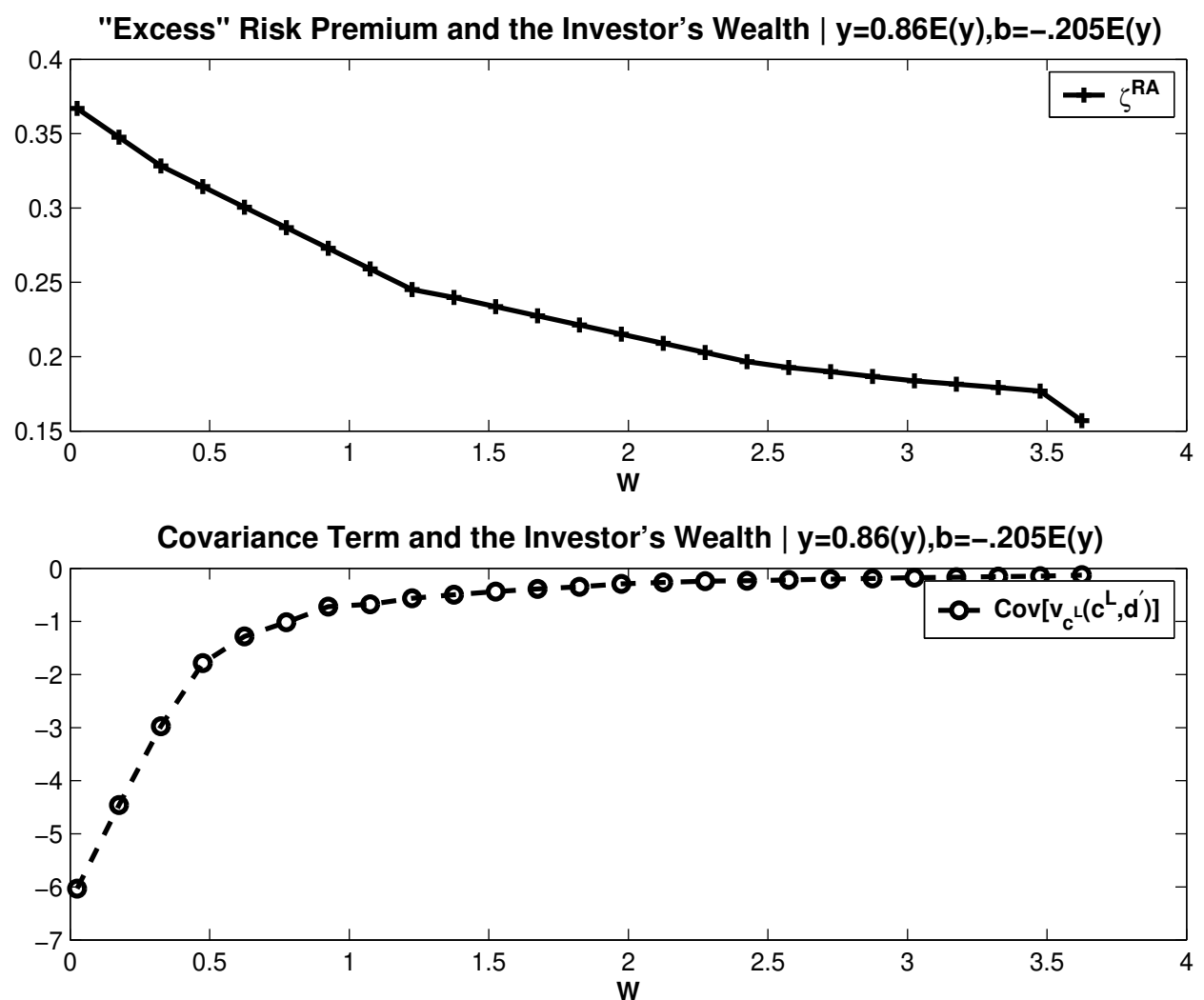

Figure 1: The Covariance Term and the Investor's Wealth Level.

is not very relevant. However for not "too high" levels of debt, the covariance term is much more negative the higher the level of the economy's debt; in turn more risky investments command a larger "excess" risk premium. For example, in the figure we observe the case in which the investor's wealth level is $2.5 \%$ of the average income of the economy, and the endowment realization of the endowment is again the lowest possible one. In this situation when the economy borrows very little - almost 0 - the "excess" risk premium is close to $20 \%$. On the other hand, when the economy borrows an amount near to $10 \%$ of the economy's average income, the "excess" risk premium amounts to a little more than $30 \%$.

Finally, in looking at the riskiness of the emerging economy's assets, increasing the riskiness should increase the "excess" risk premium. Figure 3 shows the behavior of the covariance term as function of the economy's endowment keeping fixed the asset position of the economy and the investor's wealth level and degree of risk aversion. We observe that for higher income levels, which are empirically associated with low riskiness of the 


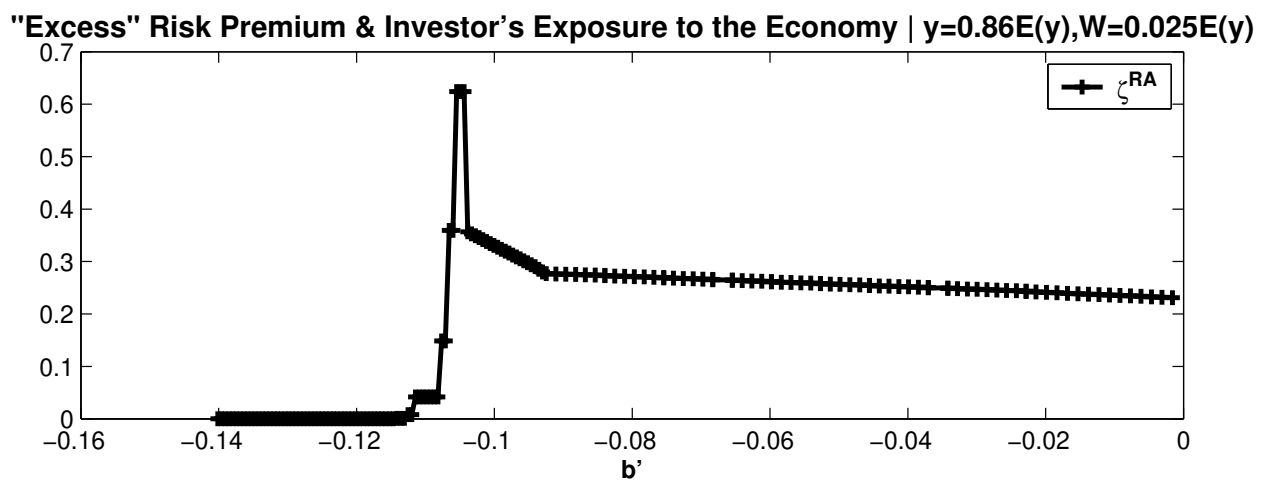

Covariance Term and Investor's Exposure to the Economy $\mid \mathrm{y}=0.86(\mathrm{y}), \mathrm{W}=\mathbf{0 . 0 2 5 E ( y )}$

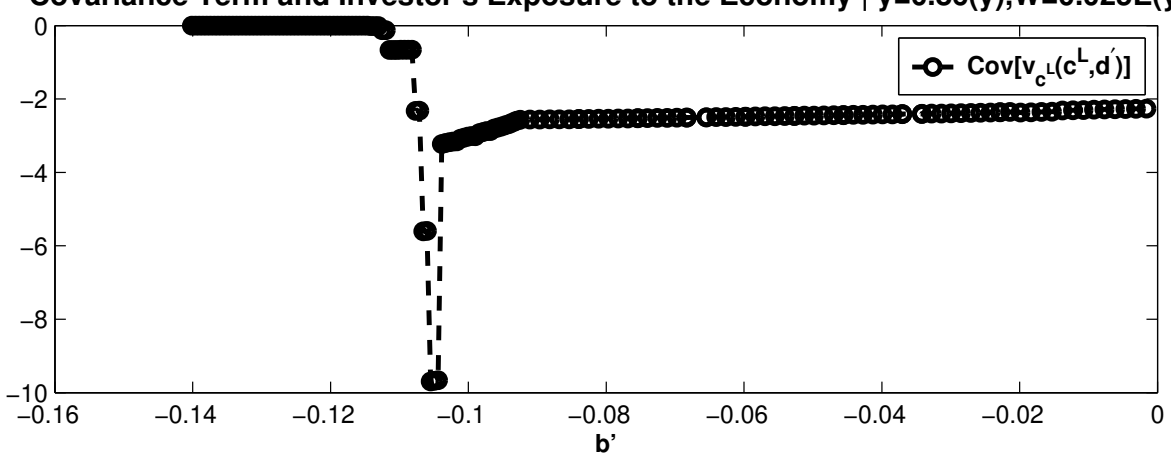

Figure 2: The Covariance Term and the Investor's Exposure to the Emerging Economy.

economy's assets, the covariance term is less negative; therefore for higher income levels, the "excess" risk premium is not as large as it is for lower income levels. For example, when the investor's wealth is $2.5 \%$ of the economy's expected income and the debt level of the economy corresponds to $20.5 \%$ of the expected income, if the economy has the largest possible endowment - income that is $20 \%$ above trend-, the "excess" risk premium is $26 \%$; but when the economy hast the lowest possible endowment - income that is $20 \%$ below trend- the "excess" risk premium is $33 \%$.

Leaving aside the behavior of the "excess" risk premium, it is important to note that the equilibrium probability of default is different in the case of a risk neutral investor, $\delta\left(s, b^{\prime}\right)$, compared to the case of a risk averse investor, $\delta^{R N}\left(s, b^{\prime}\right)$. Therefore the base risk premium (the one that compensates the investor for the probability of default) is also larger in the case of risk averse investors. In fact, for any given $s$ and $b^{\prime}$, the probability of default is an increasing function of the investor's degree of risk aversion. (This result will be studied in detail in the next section.) 


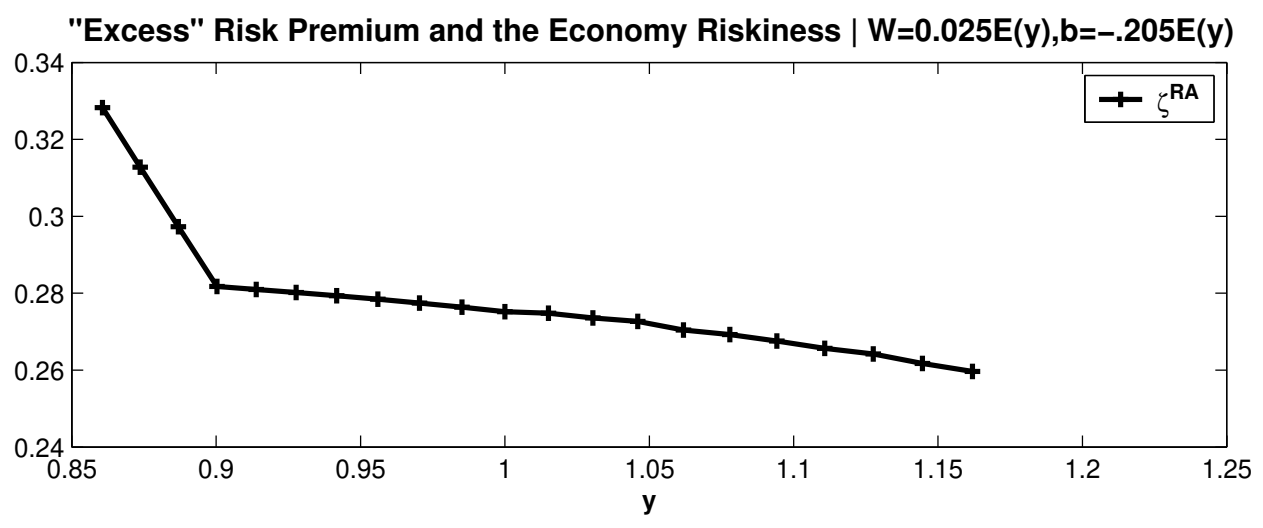

Covariance Term and the Economy Riskiness | W=0.025E(y),b=-.205E(y)

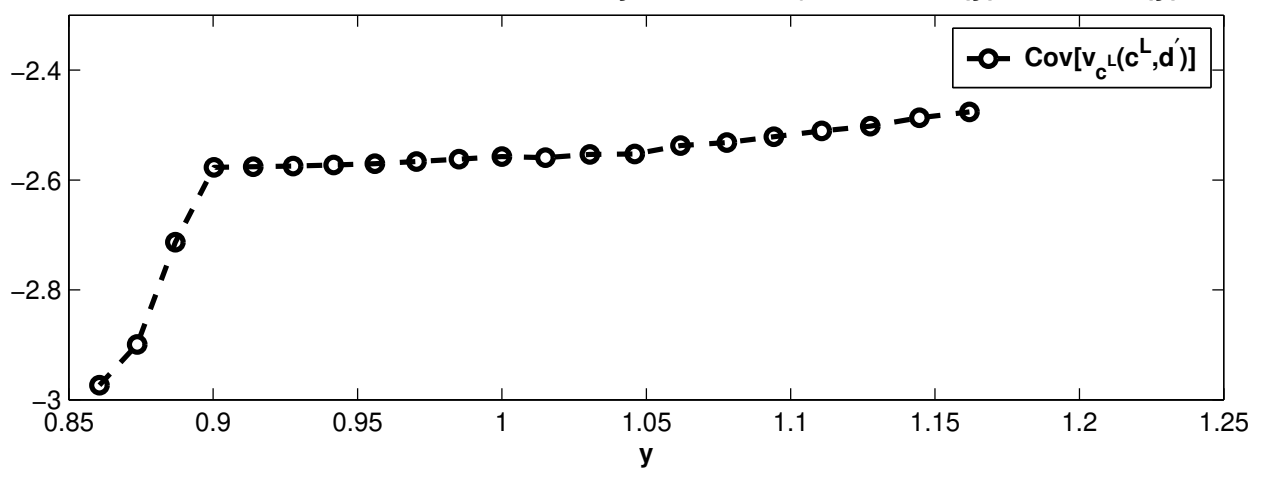

Figure 3: The Covariance Term and the the Emerging Economy's Riskiness.

Figure 4 shows default probability functions for two identical economies that trade with two different type of investors, one risk neutral and the other risk averse. For a given level of wealth, Figure 4 shows that when investors are risk averse, the probability of default is greater than or equal to the probability of default associated with the same levels of debt when investors are risk neutral. This result holds for all realizations of the economy's endowment and all levels of debt.

In conclusion, it is possible to say that for $s$ and $b^{\prime}$ given, the price of the bonds issued by the emerging economy trading with a risk averse investor, $q\left(\delta\left(s, b^{\prime}\right)\right)$, is always lower or at best equal to price of the same bonds traded with a representative risk neutral investor, $q^{R N}\left(\delta^{R N}\left(s, b^{\prime}\right)\right)$.

Compared to the case of risk neutral investors, the introduction of risk averse investors is a step forward in explaining the risk premium in the returns of bonds from emerging economies. This risk premium seems to be supported empirically since the price of emerging 

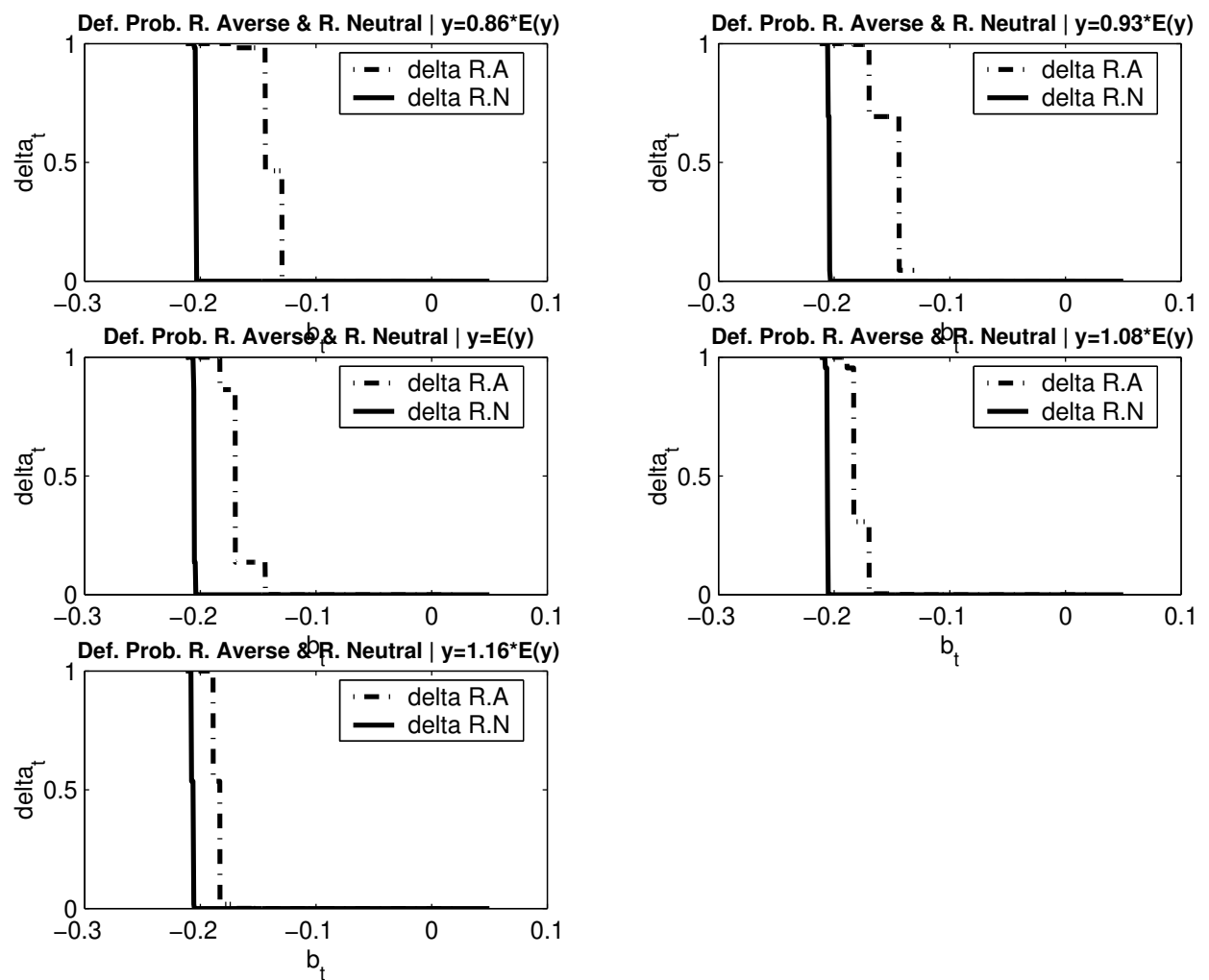

Figure 4: Default Probabilities: Risk Neutral vs. Risk Averse Investors.

economies' bonds seems to be determined by much more than just the opportunity cost of the funds adjusted by the probability of default of such economies. ${ }^{18}$ Risk aversion can help explain this phenomena since a risk averse investor would have to be compensated beyond the probability of default-adjusted rate of return in order to face the risk of default by an emerging economy. The higher the degree of risk aversion, the higher the bond spread.

\subsubsection{Non-Negativity Constraints in the Investor's Consumptionand Investor's Credit Constraints}

The solution to the investor's optimization problem is not necessarily an interior solution:

\footnotetext{
${ }^{18}$ This phenomena is discussed in Cantor and Pecker (1996) and Cunningham et al.(2001) among others.
} 
Non-Negativity Constraints in the Investor's Consumption When the nonnegativity constraints for the investor's consumption are binding, the portfolio allocation is different from the allocation reached for the interior solution for the investor's optimization problem.

In this case the expression for the bond prices of the emerging economy is:

$$
q=\frac{1}{1+\frac{\varpi}{v_{c^{L}\left(c^{L}\right)}}}\left[q^{*}+\frac{\beta_{L} \operatorname{Cov}\left[\varpi^{\prime}, d^{\prime}\right]}{v_{c^{L}}\left(c^{L}\right)}+\frac{\beta_{L} E\left[\varpi^{\prime}\right](1-\delta)}{v_{c^{L}\left(c^{L}\right)}}\right] .
$$

where $q^{*}$ corresponds to the "optimal" price of the bonds of the emerging economy (i.e. the one discussed previously and consistent with the existence of an interior solution to the investor's portfolio allocation problem), $\varpi$ is the current period multiplier of the nonnegativity constraint in consumption, and $\varpi^{\prime}$ is the lifetime multiplier for the future periods of the non-negativity constraint in consumption.

Whenever $\varpi>0$ the current period non-negativity constraint in consumption is binding and the investors need to borrow from international credit markets more than the "optimal" amount. At the same time investors invest in the emerging economy less than the "optimal" quantity.

The specific expression for the emerging economy's bond prices is:

$$
q=\frac{q^{*}}{1+\frac{\varpi}{v_{c^{L}\left(c^{L}\right)}}} .
$$

The equilibrium price of the bonds of the emerging economy is lower than the corresponding one when the non-negativity constraint for the investor's consumption of the current period is not binding.

Whenever $\varpi^{\prime}>0$ the future period's non-negativity constraint in consumption is binding. As a consequence the investors invest (in both riskless and risky bonds) more than the "optimal" amount.

The specific expression for the emerging economy's bond prices is:

$$
q=\left[q^{*}+\frac{\beta_{L} \operatorname{Cov}\left[\varpi^{\prime}, d^{\prime}\right]}{v_{c^{L}\left(c^{L}\right)}}+\frac{\beta_{L} E\left[\varpi^{\prime}\right](1-\delta)}{v_{c^{L}\left(c^{L}\right)}}\right] .
$$

The term $\frac{\beta_{L} \operatorname{Cov}\left[\varpi^{\prime}, d^{\prime}\right]}{v_{c}\left(c^{L}\right)}$ is negative: lower levels of $d^{\prime}$ imply lower levels of $c^{L^{\prime}}$ and a more binding non-negative constraint. The term $\frac{\beta_{L} E\left[\varpi^{\prime}\right](1-\delta)}{v_{c}\left(c^{L}\right)}$ is positive. Therefore two 
opposing forces are at work related to the non-negativity constraint: first, more riskiness of the emerging economy's bonds implies a higher likelihood that the investment in the emerging economy will not pay back (lower future consumption via this effect); second, more riskiness implies a larger risk premium and therefore higher earnings if the investment pays back (higher future consumption via this effect).

Given the two opposing effects, the net effect on the emerging economy's bond prices is not clear: it might be that the observed bond price is somewhat larger than it would be if the non-negativity constraint was not binding.

Investor's Credit Constraints Whenever the representative investor faces credit constraints in international credit markets the following Kuhn-Tucker conditions characterize her optimization problem:

For $\theta^{T B \prime}$

For $\theta_{j}^{\prime}$

$$
q^{f} v_{c^{L}}\left(c^{L}\right)-\mu=\beta_{L} E\left[v_{c^{L}}\left(c^{L^{\prime}}\right)\right] .
$$

$$
q=q^{*}-\frac{\mu(1-\delta)}{v_{c^{L}}\left(c^{L}\right)} .
$$

where, as before, $q^{*}$ corresponds to the bond price consistent with and interior solution for representative investor's optimization problem, and $\mu$ corresponds to the multiplier on the representative investor's credit constraint.

Given that credit constraints for the investors would increase their opportunity cost of investing in emerging economies, other things given, these constraints should reduce the equilibrium bond prices of the emerging economy even further in comparison with the default risk adjusted- price (i.e., $q^{R N}$ ).

\subsection{The Emerging Economy}

The representative agent of the emerging economy maximizes her discounted expected lifetime utility from consumption

$$
\max _{\left\{c_{t}\right\}_{t=0}^{\infty}} \quad E_{0} \sum_{t=0}^{\infty} \beta^{t} u\left(c_{t}\right)
$$

where $0<\beta<1$ is the discount factor and $c$ is the emerging economy's consumption at time $t$. The emerging economy's periodic utility takes the functional form

$$
u(c)=\frac{c^{1-\gamma}}{1-\gamma}
$$


where $\gamma>0$ is the coefficient of relative risk aversion.

In each period, the economy receives a stochastic stream of consumption goods, $y$. This endowment is non-storable; realizations of the endowment are assumed to have a compact support; and the endowment follows a Markov process drawn from probability space $(y, Y(y))$ with a transition function $f\left(y^{\prime} \mid y\right)$.

In each period, based on the stochastic endowment, $y$, the economy decides how much to consume, $c$. The economy can consume $c>y$ by trading one period non-contingent discount bonds $b^{\prime}$ at a price, $q$, with international investors.

As a consequence of commitment problems, the price of the emerging economy's bond might be different depending on whether the economy is saving or borrowing. If $b^{\prime} \geq 0$, there is not commitment problem in the side of the economy and there is no risk of default on such a bond. In this case, the emerging economy's bond is identical to the bonds issued by industrialized markets; therefore in equilibrium the bond price of a emerging economy with no default risk is the same as the bond price of industrialized countries. Consequently, the price of a bond with a positive face value is equal to the price of a T-Bill, so $q=q^{f}$.

If $b^{\prime}<0$, the emerging country is borrowing. In this case, because emerging economies cannot bind themselves to honor their debts, the emerging country might default next period. At one extreme, there might be values of $b^{\prime}<0$ for some given state of the world, $s$, such that the representative agent of the economy never finds it optimal to default. In this case the bonds issued by the emerging economy do not involve any default risk, and therefore $q=q^{f}$. At the other extreme, for the same state of the world, $s$, there might be values of $b^{\prime}<0$ such that once the debt is due the economy would not choose to repay in any state of the world next period, $s^{\prime}$. In this case $q=0$. In the intermediate case, for the same state of the world, $s$, some other values of $b^{\prime}<0$ might imply that the emerging economy will find it optimal to default on her debts in some states of the world next period $s^{\prime}$. In this case, in order to induce international investors to buy the emerging economy's bonds, the price of such bonds needs to be lower than the price of a T-Bill, $q<q^{f}$.

As consequence, the price of the emerging economy's bonds is a function not only of the state of the world, $s$, but also of $b^{\prime}$.

The resource constraint of the emerging economy is given by

$$
c=y-(1-d) \phi+d\left(b-q b^{\prime}\right)
$$

where $d$, which has been defined in the investor's section, describes the state of the economy with respect to participation in international financial markets. If $d=1$, the economy is not 
in a state of default. If $d=0$ the emerging economy is in a state of default (either because she has defaulted on her debts in a previous period and has not regained access to financial markets or because she is defaulting on her debts in the current period) and the country is currently in financial autarky. Once a country defaults, that country is excluded from access to the credit market, and that country remains in a state of default for a random number of periods. During the periods of exclusion of financial markets the country is not able to smooth its consumption, and it is limited to consume its stochastic endowment minus some amount given by a function $\phi$ that defines the direct loss in terms of endowment that the country faces during the periods of exclusion from credit markets.

Under this framework, the optimization problem of the emerging country can be represented recursively by the following Bellman equation

$$
V(s)=\max \left\{V^{C}(s), V^{D}(s)\right\}
$$

and

$$
\begin{aligned}
V^{C}(s) & =\max _{c, b^{\prime}} u(c)+\beta E V\left(s^{\prime} \mid s\right) \\
\text { s.t. } \quad c & =y+b-q b^{\prime}
\end{aligned}
$$

where $V^{C}(s)$ is the value to the economy of not defaulting and $V^{D}(s)$ is the value of defaulting in the current period.

Definition 2 The value for the emerging economy of default is given by

$$
V^{D}(s)=u(y-\phi)+\beta E\left[\tau V^{C}\left(s^{\prime} \mid s\right)+(1-\tau) V^{D}\left(s^{\prime} \mid s\right)\right] .
$$

$\tau$ is the exogenous probability that the emerging economy would re-enter credit markets in the current period given that this economy has defaulted in her debts in a previous period.

For the emerging country the decision of default/repayment depends on the comparison between the value of continuing in the credit contract, $V^{C}(s)$, versus the value of opting of financial autarky, $V^{D}(s)$. The decision of current default/repayment takes the functional form

$$
d=\left\{\begin{array}{ll}
1 & \text { if } V^{C}(s)>V^{D}(s) \\
0 & \text { otherwise }
\end{array}\right\}
$$

Conditional on the representative investor's wealth level, the emerging economy's default policy can be characterized by default sets: 
Definition 3 For a given level of wealth, $W$, the default set $D(b \mid W)$ consists of the equilibrium set of $y$ for which default is optimal when the emerging economy's asset holdings are $b$ :

$$
D(b \mid W)=\left\{y \in Y: V^{C}(b, y) \leq V^{D}(y) \mid W\right\} .
$$

Equilibrium default sets, $D\left(b^{\prime} \mid W^{\prime}(s)\right)$, are related to equilibrium default probabilities, $\delta\left(b^{\prime}, y^{\prime} \mid s\right)$, by the equation

$$
\delta\left(b^{\prime}, y^{\prime} \mid s\right)=1-E d^{\prime}\left(b^{\prime}, y^{\prime} \mid s\right)=\int_{D\left(b^{\prime} \mid W^{\prime}(s)\right)} f\left(y^{\prime} \mid y\right) d y^{\prime} .
$$

If the default set is empty for $b^{\prime}$, then for all realizations of the economy's endowment, $d^{\prime}=1$ and the equilibrium default probability $\delta\left(b^{\prime}, y^{\prime} \mid s\right)$ is equal to 0 . In this case, it is not optimal for the economy to default in the next period for any realization of its endowment, and $\operatorname{Cov}\left[v_{c^{L}}\left(c^{L^{\prime}}\right) d^{\prime}\right]=0$ and $q=q^{f}$. On the other hand, if the default set includes the entire support for the endowment realizations, i.e. $D\left(b^{\prime} \mid W^{\prime}(s)\right)=Y$, then $d^{\prime}=0$ for all realizations of the economy's endowment. As a consequence, the equilibrium default probability $\delta\left(b^{\prime}, y^{\prime} \mid s\right)$ is equal to 1 , and $\operatorname{Cov}\left[v_{c^{L}}\left(c^{L^{\prime}}\right) d^{\prime}\right]=0$, so $q=0$.

Otherwise, when the default set is not empty but does not include the whole support for the endowment realizations, $0<\delta\left(b^{\prime}, y^{\prime} \mid s\right)<1$. In this case, which was analyzed in the section describing the investors' optimization problem, $\operatorname{Cov}\left[v_{c^{L}}\left(c^{L^{\prime}}\right) d^{\prime}\right]>0$, so $q<q^{f}$.

Equations (10),(13),(15),(16) and (17) make clear that for the case of an economy that cannot commit to repayment, when there exist levels of $b^{\prime}$ in which the emerging economy finds it optimal to default in some states of the world, then the price of bonds depends not only on the emerging economy's fundamentals, but on the representative investor's level of wealth and risk aversion. This case is very different from the case of an identical small open economy that faces risk neutral investors in international financial markets. As can be seen in other models of the sovereign debt literature when investors are risk neutral, the price of bonds of the economy depends only on the economy's own fundamentals and characteristics.

\section{Characterization of the Equilibrium}

The recursive equilibrium for this model is defined as a set of policy functions for (i) the emerging economy's consumption $c(s)$, (ii) the emerging economy's asset holdings $b^{\prime}(s)$, 
(iii)the emerging economy's default decisions $d(s)$ and the associated default sets $D(b \mid W)$, (iv) the representative investor's consumption $c^{L}(s)$, (v) the representative investor's holdings of emerging economy's bonds $\theta^{\prime}(s)$, (vi) the representative investor's holdings of T-Bills $\theta^{T B^{\prime}}(s)$, and (vii) the emerging economy's bond price function $q\left(s, b^{\prime}\right)$ such that:

(i) Taking as given the representative investor's policies, and the bond price function $q\left(s, b^{\prime}\right)$, the emerging economy's consumption $c(s)$ satisfies the economy's resource constraint. Additionally, the economy's policy functions $b^{\prime}(s), d(s)$ and default sets $D(b \mid W)$ satisfy the optimization problem of this emerging economy.

(ii) Taking as given the emerging economy's policies, and the bond price function $q\left(s, b^{\prime}\right)$ the representative investor's consumption $c^{L}(s)$ satisfies the investor's budget constraint. Also, the representative investor's policy functions $\theta^{\prime}(s)$ and $\theta^{T B^{\prime}}(s)$ satisfy the optimization problem of the representative investor, and the law of motion of the investor's wealth.

(iii) Bond prices reflect the emerging economies probability of default and the risk premium demanded by the representative international investor, and these prices clear the market for the emerging economy's bonds:

$$
\begin{aligned}
b^{\prime}(s)=-\theta^{\prime}(s) & \text { if } \quad b^{\prime}(s)<0 \\
0=-\theta^{\prime}(s) & \text { if } \quad b^{\prime}(s) \geq 0 .
\end{aligned}
$$

This condition implies that the representative investor and the representative agent of the emerging economy agree on a financial contract $\left(b^{\prime}, q\right)$ that is optimal for both agents.

\subsection{Characterization of Default Sets}

The characterization of default sets is the characterization of incentives to default and therefore the characterization of endogenous default risk. In this model, default risk is a function of both the emerging economy's fundamentals - the economy's endowment process and its asset position - and the characteristics of the international investor - the investor's risk aversion and wealth.

Maximum Credit Constraint and Maximum Safe Level of Debt In order to continue with the characterization of the default sets it is necessary to define two concepts, the maximum credit constraint and the maximum safe level of debt. The maximum credit 
constraint is the maximum level of assets, $\underline{b}(W)$, that is low enough such that no matter what the realization of the endowment, default is the optimal choice and $D(\underline{b}(W) \mid W)=Y$. On the other hand, the maximum safe level of debt is the minimum level of assets $\bar{b}(W)$ for which staying in the contract is the optimal choice for all realizations of the endowment. In this case, $D(\bar{b}(W) \mid W)=\emptyset$. Finally, because the value of the credit contract is monotonically decreasing in $b$, it is obvious that

$$
\underline{b}(W) \leq \bar{b}(W) \leq 0 \quad .
$$

Proposition 1 For any state of the world, $s$, the maximum credit constraint, $\underline{b}(W)$, and the maximum safe level of debt, $\bar{b}(W)$, are singled-valued functions.

Proof. To define these concepts, note that the stochastic process for the endowments has a compact support. Also note that, conditional on $W$, the value of the credit contract is monotonically decreasing in $b$. Monotonicity of the credit contract and compactness of the endowment support are sufficient conditions to guarantee that given the state of the world, these critical values (i.e. maximum credit constraint and maximum safe level of debt) are single-valued functions.

From the previous discussion it is clear that given some current level of investors' wealth, any investment in the emerging economy's bonds in excess of $\underline{b}(W)$ would imply a probability of default equal to 1 . These investments will have a price of 0 . On the other hand, all investments in the emerging economy's bond of an amount lower than $\bar{b}(W)$ imply a zero probability of default. These investments will have a price of $q^{f}$.

Default Sets and Risk Aversion of International Investors The degree of investors' risk aversion is an important determinant of access of emerging economies to credit markets, and of the risk of default of the economy. In this model, the more risk averse are international investors, the higher is the default risk and the tighter is the endogenous credit constraint faced by all emerging economies.

Proposition 2 For any state of the world, s, as the risk aversion of the international investor increases, the emerging economy's incentives to default increase.

Proof. See Appendix.

The economic intuition behind this result is straightforward for the case of permanent exclusion from credit markets following a default. In this case, for the emerging economy, 
while the value of autarky is not a function of the investor's risk aversion, the value of maintaining access to credit markets is decreasing in the investor's degree of risk aversion. In order to induce a very risk averse investor to hold sovereign bonds, the emerging economy has to forgo much more current consumption-i.e. has to accept a very low price for her bonds. However, other things equal, with lower bond prices, incentives to default are stronger. Therefore for any given state of the world, $s$, the degree of risk in the economy is increasing in the degree of risk aversion of international investors.

When the exclusion from credit markets following default is not permanent, both the value of financial autarky and the value of maintaining access to credit markets are functions of the investor's risk aversion. The value of autarky in the current period includes the value of maintaining access to the credit markets in future periods once the economy is admitted back to the credit markets; therefore is also decreasing in the investor's degree of risk aversion. However the value of maintaining access to credit markets in future periods is weighted by the probability of coming back (which is lower than 1) and the discount rate (which is also lower than 1). As a consequence, the response of the value of autarky in the current period to the risk aversion of international investors is smaller than the response of the value of maintaining access to credit markets in the current period to the risk aversion of these investors. Therefore, the degree of risk in the economy is increasing in the degree of risk aversion of international investors, as in the case of permanent punishment after a default.

As the degree of risk in the economy changes, so too will the capital flows to the economy: For $\gamma_{L}^{1}<\gamma_{L}^{2}$, Proposition 2 implies that

$$
D\left(b \mid W ; \gamma_{L}^{1}\right) \subseteq D\left(b \mid W ; \gamma_{L}^{2}\right) .
$$

Therefore, it must hold that

$$
\begin{aligned}
& \underline{b}\left(W ; \gamma_{L}^{2}\right) \geq \underline{b}\left(W ; \gamma_{L}{ }_{L}\right) . \\
& \bar{b}\left(W ; \gamma_{L}^{2}\right) \geq \bar{b}\left(W ; \gamma_{L}{ }_{L}\right) .
\end{aligned}
$$

This equation shows that maximum credit constraints $\underline{b}(W)$ for the emerging economy are tighter the more risk averse are international investors - some contracts that are feasible under less risk averse investors are not feasible under more risk averse investors.

The result in Proposition 2 is consistent with empirical findings which characterize the role of investor's risk aversion in the determination of country risk and sovereign yield. ${ }^{19}$

\footnotetext{
${ }^{19}$ Much empirical evidence supports Proposition 2: Using the spread between the yield of three month T-bills and the US federal funds rate as a proxy for market turbulence, Arora and Cerisola (2001) find that
} 
Default Sets and Investor's Wealth In the present model, the economic performance of the emerging economy cannot be explained by the fundamentals of the emerging economy alone, i.e. by the economy's asset position and stochastic process of the endowment. The investor's wealth also affects the emerging economy's performance. This result is formalized in Proposition 3.

Proposition 3 Default sets are shrinking in assets of the representative investor. For all $W_{1}<W_{2}$, if default is optimal for $b$ in some states $y$, given $W_{2}$, then default will be optimal for $b$ for the same states $y$, given $W_{1}$. Therefore $D\left(b \mid W_{2}\right) \subseteq D\left(b \mid W_{1}\right)$

Proof. See Appendix.

The intuition for Proposition 3 is simple: given some default risk, it is less costly (in terms of current utility) for the investor to invest in the emerging economy when she is wealthy than when she is poor. So keeping constant the degree of risk that the investor faces, any investment that she is willing to undertake when she is poor she will also be willing to undertake when she is rich. Intuitively, financial contracts available to the representative agent of the emerging economy when the investor is relatively rich have to be at least as good as the feasible contracts to which the economy has access when the investor is relatively poor. Additionally, the previous effect implies that the emerging economy faces stronger incentives to default when the wealth of the investor is relatively low. Therefore default risk is decreasing in the wealth of the investor. These two effects amplify and reinforce each other.

Proposition 3 implies that for $W_{1}<W_{2}$ it must hold

$$
\begin{aligned}
& \underline{b}\left(W_{1}\right) \geq \underline{b}\left(W_{2}\right) \\
& \bar{b}\left(W_{1}\right) \geq \bar{b}\left(W_{2}\right)
\end{aligned}
$$

and therefore the maximum credit limit that the emerging economy faces is tighter for lower levels of wealth of the investor $\left(\underline{b}\left(W_{1}\right) \geq \underline{b}\left(W_{2}\right)\right)$.

heightened macroeconomic uncertainty in the US, has a positive significant effect on sovereign credit spreads for emerging markets. Using high-low yield spreads on US corporate bonds as a proxy for risk aversion of US investors, Ferruci et al.(2004) and FitzGerald and Krolzig (2003) find that sovereign bond spreads increase when the risk aversion of US investors increases. Similarly, Cunningham et al. (2001), Westphalen (2001), and Kamin and von Kleist (1999) find evidence that the risk premium in sovereign bonds increases more than proportionally when default risk increases. Finally, Mody and Taylor (2004), Ferruci et al.(2004), and FitzGerald and Krolzig (2003) find that risk aversion of US investors is an important determinant of capital flows to emerging economies: a higher US high-low yield spread-interpreted as a reduction in investor risk appetite - results in a reduced supply of capital to emerging economies. 
This result is a consequence of the fact that for investors, the marginal cost of investing in sovereign bonds in terms of current consumption is decreasing in investors' wealth. Given that investors are risk averse with decreasing absolute risk aversion, investing in the sovereign bonds when their wealth is low is too costly; so when the wealth of the investor falls, the resources available to the emerging economy become scarce, reducing the value for the emerging economy of participating in credit markets. In turn, because the sovereign country has increasing incentives to default, some loans or portfolio investments that are feasible when the investor is wealthy cannot be an equilibrium outcome when the investor is poor.

Findings of several empirical papers on the literature regarding the determinants of capital flows and sovereign bonds spreads of emerging economies are consistent with the results in Proposition 3. See, for example, Warther (1995), Westphalen (2001), FitzGerald and Krolzig (2003), Mody and Taylor (2004), and Ferruci et al.(2004).

The results in Proposition 3 are also consistent with the evidence regarding financial contagion across countries who share investors. See for example Kaminsky and Reinhart (1998), Kaminsky and Reinhart (2000), Hernandez and Valdes (2001) andVan Rijckeghem and Weder (2001). ${ }^{20}$

Default Sets and the Asset Position of the Emerging Economy In the model, a highly indebted economy is more likely to default than an economy with lower debt. And as in models of the same type where investors are risk neutral, default sets are shrinking in assets.

Proposition 4 Default sets are shrinking in assets of the emerging economy. For all $b_{1}<$ $b_{2}$, if default is optimal for $b_{2}$ in some states $y$, given $W$, then default will be optimal for $b_{1}$ for the same states $y$, given $W$. Therefore $D\left(b_{2} \mid W\right) \subseteq D\left(b_{1} \mid W\right)$.

\footnotetext{
${ }^{20}$ For the period 1984 to 1993 , Warther (1995) finds that an inflow to corporate bond funds of around $1 \%$ of the mutual fund's assets results in a permanent increase of $2.1 \%$ in those bond prices (i.e. reduces the cost of borrowing for those issuing those bonds). Using world and U.S. equity indexes respectively as proxies for the business climate (an increase in these indexes is associated with a better business climate), Westphalen (2001) and Ferruci et al. (2004) find a negative relation between economic expansion in the investors' countries and sovereign yield spreads of emerging economies. FitzGerald and Krolzig (2003) find a positive and significant relationship between US output and capital inflows to emerging economies. Finally, Mody and Taylor (2003) find that a higher growth in industrial production in the US has a positive effect on the supply of capital to emerging economies.
} 
This result is analogous to the result in Arellano (2008), and closely related to the results in Eaton and Gersovitz (1981) and Chatterjee, et al. (2002). The main difference in the present paper is that the result is conditioned on the level of wealth of the representative investor.

The economic intuition is simple for the case in which the punishment for defaulting is permanent exclusion from credit markets: While the value for the economy of fulfilling the contract is increasing in $b$, the outside value of the economy is not - the value of financial autarky does not depend on $b$. Therefore as the indebtedness of the economy increases, the value of the contract decreases, while the value of default remains unchanged. As a consequence, starting from an asset position $b$ in which default is the optimal choice, it is clear that if the assets shrink, the value of the contract also falls. As the value of the contract falls, default will continue to be the optimal choice.

The quantitative analysis of the model suggests that this result also holds in the more general case in which exclusion from credit markets is temporary.

Default Sets and Capital Inflows The emerging economy only defaults when it is facing capital outflows. In this case, $d(s)=0$ implies that for all the financial contracts available to the economy, $b-q\left(s ; b^{\prime}(s)\right) b^{\prime}(s)<0$.

Intuitively, whenever the emerging economy decides to default, the value of default must be at least as good as the value of the optimal financial contract available to this country $\left(V^{C}(s) \leq V^{D}(s)\right)$. However if any available financial contracts allows for capital inflows to the emerging economy, then by choosing that contract the economy not only can consume more in the current period than under default $(c \geq y-\phi)$, but in the next period the economy is guaranteed at least the same level of satisfaction as under default (because the economy has the option of defaulting in the next period). Therefore for any state of the world $s$, whenever there are financial contracts $\left\{q\left(s ; b^{\prime}(s)\right), b^{\prime}(s)\right\}$ such that $b-q\left(s ; b^{\prime}(s)\right) b^{\prime}(s)>0$, default is not an optimal decision.

Default Sets and Endowment Realization Default sets also depend on the realization of income. As in Arellano (2008), it is possible to show analytically that for the case of permanent exclusion of the emerging economy from credit markets after defaulting, if the endowment process is i.i.d. for given $W$, then default incentives are stronger for lower levels of income.

The numerical solution of the present model extends this result to the more general 
case in which the exclusion of the emerging economy from credit markets after defaulting is not permanent and the stochastic process of her endowments follows a Markov chain with persistence.

Proposition 5 If the endowment process is i.i.d., default incentives are stronger the lower the endowment. For all $y_{1}<y_{2}$, if $y_{2} \in D(b \mid W)$ then $y_{1} \in D(b \mid W)$.

The intuition for this result follows Arellano (2008). Again, the main difference is that in the present context, the result is conditioned on the level of wealth of the investors. The logic behind this results follows from the fact that default is only optimal if under all feasible financial contracts the emerging economy experiences capital outflows. In the case of a recession, capital outflows are extremely costly in terms of the welfare of a risk averse agent (because the concavity of the periodic utility); therefore at sufficiently low levels of the endowment realization, the credit market becomes a less effective tool for consumption smoothing than default.

This result is also consistent with the empirical literature on the determination of credit ratings and sovereign yields. In this literature, sovereign yield spreads increase when the economy's fundamentals deteriorate, mainly when output falls.

Additionally, this result implies that because default risk is counter-cyclical, domestic interest rates are also counter-cyclical. Counter-cyclicality is consistent with the stylized facts of financial emerging markets (see Neumeyer and Perri (2005), and Uribe and Yue (2006)).

\subsection{Default as an equilibrium outcome of the model and Investors char- acteristics}

In the current model to observe default at equilibrium it must hold that beginning from an asset position $b$ such that $D(b \mid W)=\emptyset$, there exists a sequence of endowment shocks such that this economy ends up borrowing $b^{\prime}$ and $D\left(b^{\prime} \mid W^{\prime}(s)\right) \neq \emptyset$.

From the definitions of the maximum credit constraint $\underline{b}\left(W^{\prime}\right)$ and the maximum safe level of debt $\bar{b}\left(W^{\prime}\right)$, it is clear that any $b^{\prime}$ for which $D\left(b^{\prime} \mid W^{\prime}(s)\right) \neq \emptyset$ satisfies $b^{\prime} \in$ $\left(\underline{b}\left(W^{\prime}\right), \bar{b}\left(W^{\prime}\right)\right)$. A necessary condition for the economy to optimally choose to borrow $b^{\prime}$ instead the maximum safe level of debt $\bar{b}\left(W^{\prime}(s)\right)$ is that by doing so the economy is able to increase its current consumption. If by borrowing $b^{\prime}$ instead of $\bar{b}\left(W^{\prime}(s)\right)$ the economy does not increases its current consumption then $b^{\prime}$ is not optimal: not only does the economy not 
achieve a higher level of consumption this period by choosing $b^{\prime}$, but the debt obligations pending for next period are larger than if the economy had borrowed $\bar{b}\left(W^{\prime}(s)\right)$ instead.

In order to establish if default might be an equilibrium outcome of the model, it is necessary to determine if there exists some $b^{\prime}<\bar{b}\left(W^{\prime}(s)\right)$ for which by increasing its borrowing beyond the maximum safe level of debt the economy is able to increase its current capital inflows $-q\left(s, b^{\prime}\right) b^{\prime}$.

Following closely the analysis in Arellano (2008) and focusing on the case in which incentives to default are stronger the lower the endowment, it is possible to define the conditional default boundary function $y^{*}(b \mid W)$ as follows: ${ }^{21}$

Definition 4 The conditional default boundary function $y^{*}(b \mid W)$ corresponds to the endowment level $y^{*}$ for a given level of debt $b \in(\underline{b}(W), \bar{b}(W))$ conditional on the representative investor's assets $W$ which makes the value of repayment and the value of default equal for the emerging economy: $V^{C}\left(b, y^{*}, W\right)=V^{D}\left(y^{*}, W\right)$.

Conditional on the investor's wealth $W, y^{*}(b \mid W)$ divides the space $\{y, b\}$ into the default and repayment regions. As a consequence of proposition 4 , the conditional default boundary is decreasing in the emerging economy's assets. Furthermore, as result of proposition 3 the conditional default boundary is also decreasing on the investor's assets. Finally, due to proposition 2 this function is increasing in the investor's risk aversion.

Using the definition of bond prices in equation (10), together with the definition of default probabilities in equation (17), it is possible to show that as in the case of risk neutral investors, the equilibrium bond price, $q\left(s, b^{\prime}\right)$, is a function of the default boundary, $y^{*}\left(b^{\prime} \mid W^{\prime}(s)\right)$, and the distribution of shocks.

However, for the case of risk averse investors both the investors' risk aversion $\gamma^{L}$ and their wealth level $W$ affect the bond prices: besides helping to determine the default boundary $y^{*}\left(b^{\prime} \mid W^{\prime}(s)\right), \gamma^{L}$ and $W$ also help to determine the excess risk premium included in the

\footnotetext{
${ }^{21}$ The case in which incentives to default for the emerging economy are stronger when endowments are low seems to be the empirically relevant case as long as the persistence of the endowment shocks is not too high.
} 
equilibrium bond prices:

$$
\begin{aligned}
q\left(s, b^{\prime}\right) & =q^{f}\left[1-F\left(y^{*}\left(b^{\prime} \mid W^{\prime}(s)\right)\right)\right]+\beta_{L} \frac{\left[\operatorname{Cov}\left(v_{c^{L}}\left(c^{L^{\prime}}(s)\right), d^{\prime}(s)\right)\right]}{v_{c^{L}}\left(c^{L}(s)\right)} \\
& =\int_{y^{*}\left(b^{\prime} \mid W^{\prime}(s)\right)}^{Y} \beta_{L} \frac{v_{c^{L}}\left(c^{L^{\prime}}(s)\right)}{v_{c^{L}}\left(c^{L}(s)\right)} f\left(y^{\prime} \mid y\right) d y^{\prime} .
\end{aligned}
$$

where $F$ is the cumulative probability distribution of shocks.

Financial contracts $\left\{q\left(s, b^{\prime}(s)\right), b^{\prime}(s)\right\}$ observed at equilibrium change current consumption by the product $-q\left(s, b^{\prime}(s)\right) b^{\prime}(s)$. As consequence of the result in proposition 4 , the definition of the conditional boundary function, and the definition of equilibrium bond prices, as debt increases the equilibrium bond prices go to zero. Therefore it is possible to define the endogenous borrowing limit $b^{*}(s)$ as follows:

Definition 5 The endogenous borrowing limit $b^{*}(s)$ is the level of debt for which $\pi \equiv$ $-q\left(s, b^{*}(s)\right) b^{*}(s)$ is such that

$$
\pi=\max _{b^{\prime}}\left[-\left(q^{f}\left[1-F\left(y^{*}\left(b^{\prime} \mid W^{\prime}\right)\right)\right]+\frac{\beta_{L}\left[\operatorname{Cov}\left(v_{c^{L}}\left(c^{L^{\prime}}\right), d^{\prime}\right)\right]}{v_{c^{L}}\left(c^{L}\right)}\right) b^{\prime}\right] .
$$

For any given state $s, b^{*}(s)$ is the endogenous borrowing constraint since for any $b^{\prime}<b^{*}(s)$ $V^{C}\left(s, b^{\prime}\right)<V^{C}\left(s, b^{*}(s)\right)$, and therefore $b^{\prime}<b^{*}(s)$ cannot be optimal.

As for the case of risk neutral investors, for any state $s$ the relevant risky region of the model is limited to contracts with $b^{\prime} \in\left[b^{*}(s), \bar{b}\left(W^{\prime}\right)\right)$.

Proposition 6 A necessary condition to observe default at equilibrium is that for some state $s$ the relevant risky region of the model is not empty. In other words, default is a possible outcome of the time series of the model only if there exists some $b^{*}(s)$ such that

$$
b^{*}(s)<\bar{b}\left(W^{\prime}\right) .
$$

In order to observe default at equilibrium the equilibrium price function cannot decrease "too fast" when assets decrease.

Given the speed at which bond prices decrease when the economy's assets decrease, the smaller is $\bar{b}\left(W^{\prime}(s)\right)$, the higher is the chance that there exists $b^{*}(s)<\bar{b}\left(W^{\prime}(s)\right)$. 
Intuitively, because investors must be compensated in order to induce them to take some default risk, this risk imposes an additional cost of borrowing for the emerging economy. For the borrower, the cost of borrowing beyond the maximum safe level must be paid over the total amount of resources borrowed, and not only over the marginal amount of borrowing. Therefore, the larger is the base over which this additional cost of borrowing has to be paid - i.e. the larger is the maximum safe level of borrowing - the higher is the cost of default risk and the lower is the likelihood that the economy would ever choose to borrow beyond the safe level of debt.

Role of $W$ in the determination of the existence of $b^{*}(s)<\bar{b}\left(W^{\prime}(s)\right)$. First, because of Proposition 3 a higher level of investors' wealth allows the emerging economy to borrow more. This effect implies that when investors are wealthier, other things equal, default risk imposes a larger additional cost of borrowing beyond the safe level of debt. In this case, any change in $q\left(s, b^{\prime}\right)$ will be felt over a larger base of borrowing. As a result, for the emerging economy there is potentially less to gain from accepting a lower price for these bonds in order to further increase borrowing. This effect makes it more difficult for the economy to increase consumption by risking default. Consequently, this effect implies that it should be easier to observe default as an equilibrium outcome when international investors are relatively constrained financially compared to when investors are relatively solvent.

Second, a higher level of investors' wealth reduces the absolute risk aversion of these agents. As a consequence, because the investors demand a relatively small excess risk premium, sovereign bond prices change "more slowly".

These two effects effect default probability in opposite directions. Therefore, is not possible to establish analytically how the equilibrium default probability of the model responds to changes in the wealth level of the investors. The numerical simulations of the model performed here suggest that this effect can go either way.

Role of $\gamma_{L}$ in the determination of the existence of $b^{*}(s)<\bar{b}\left(W^{\prime}(s)\right)$. First, Proposition 2 establishes that the more risk averse investors are, the less the economy is able to borrow and the lower is the maximum safe level of borrowing for any given state of the world. Therefore, other things equal, if investors are very risk averse, the cost of a change in the price of the bonds is felt over a smaller borrowing base. In this case, there is potentially more to gain from accepting a lower price for these bonds in order to further increase borrowing. Therefore this effect makes default a more likely outcome of the model. 
Table 1: Business Cycle for Argentina and International Investors

\begin{tabular}{||c|c|c|c|c||}
\hline \hline & $\operatorname{std}(\mathrm{x})$ & corr(x,output) & corr(x,sp 500) & corr(x,spread) \\
\hline \hline Interest Rate Spread & 5.42 & -0.60 & -0.39 & \\
Trade Balance & 1.83 & -0.59 & -0.07 & 0.38 \\
Consumption & 1.94 & 0.93 & 0.35 & -0.78 \\
Output & 1.91 & & 0.15 & -0.08 \\
Consumption USA & 0.31 & -0.08 & 0.40 & -0.10 \\
Output USA & 0.40 & & 0.50 & \\
SP500 & 14.79 & 0.15 & & -0.30 \\
Dow & 11.22 & 0.11 & 0.94 & \\
\hline \hline
\end{tabular}

Second, larger risk aversion of investors also implies a larger response of $q\left(s, b^{\prime}\right)$ to changes in the borrowing level. Other things equal, the more risk averse investors are, the larger is the excess risk premium that they demand in order to take default risk.

Again these two effects go in opposite directions. Therefore, is not possible to establish analytically how the equilibrium default probability of the model responds to changes in the investor's risk aversion. The numerical simulations of the model performed here also suggest that this effect can go either way.

\section{Quantitative Analysis}

Following the recent literature on endogenous sovereign default risk, the model in this paper is used to study the case of Argentina and its default at the end of 2001. The idea is to compare the quantitative performance of the model of endogenous sovereign risk with risk averse investors to the performance of the model of endogenous sovereign risk with risk neutral investors. The model is solved numerically at a quarterly frequency and its parameters are chosen to replicate important features of the Argentinean economy and the international investors in emerging economies for the period 1983:Q1-2001:Q4. In order to draw clear implications of what considering risk aversion can add to the existing literature on the dynamics of emerging economies, some parameters are not calibrated to match specific targets in the data, but instead are taken from the previous literature on the subject of endogenous sovereign risk that looks at the Argentinean default.

Table 1 describes the relevant business cycle features for the period under study. For the Argentinean output, consumption and trade balance, and for the U.S. output and consumption the source of the data is the IFS; for the yield of 3-months U.S. Treasury Bills the source is the Federal Reserve Board; for the SP500 index and the Dow-Jones Industrial Average index the source is Bloomberg; finally for the interest rate of Argentina the source 
Table 2: Parameter Values

\begin{tabular}{||l||c||}
\hline \hline Parameter & Value \\
\hline \hline Emerging Economy's Mean Income $E[y]$ & 1 \\
Std. Dev. Emerging Economy's Income $s t d[y]$ & 0.025 \\
Autocorr. Emerging Economy's Income Process & 0.945 \\
Emerging Economy's Mean Income $E[y]$ & 1 \\
Emerging Economy's Discount Factor $\beta$ & 0.953 \\
Emerging Economy's Risk Aversion $\gamma$ & 2 \\
Probability of re-entry $\tau$ & 0.282 \\
Critical level of output for asymmetrical output cost & $\hat{y}=0.969 E(y)$ \\
Representative investor's Income $X$ & 0.01 \\
Representative Investor's Discount Factor $\beta^{L}$ & 0.98 \\
Representative investor's Risk Aversion $\gamma^{L}$ & 2 \\
Risk Free Interest Rate $r^{f}=\frac{1}{q^{f}}$ & 0.017 \\
\hline \hline
\end{tabular}

is Neumeyer and Perri (2005). The data for the business cycle statistics includes the period 1983:Q1-2001:Q4 for all series except for Argentina's private consumption. For Argentina's private consumption data is only available from 1993:Q1 on. Therefore for this variable the business cycle statistics corresponds to the period from the initial moment in which it is available to first quarter of 2008. Output and consumption for Argentina and the U.S., and the sp500, and the Dow-Jones indexes are seasonally adjusted and in logs and filtered with the H-P filter. The Argentinean trade balance is reported as a percentage of the output. The interest spread is defined as the difference between the Argentinean interest rate and the yield of a 3 month U.S. T-Bill.

As has been documented in the previous literature on the subject of default risk, interest rate spreads are negatively correlated with the Argentinean output and consumption. The model in this paper matches this correlation; additionally, if we consider that investor's wealth can be proxy by either the U.S. output, the Dow-Jones index or the SP500 index, the model is consistent with the observed correlation between spreads and international investors wealth. ${ }^{22}$.

\subsection{Calibration}

Table 2 gives the parameters which are considered in the numerical analysis of the model. As previously stated, to make the comparison straightforward between the results of this model and the model of endogenous sovereign risk with risk neutral investors, the parameters for

\footnotetext{
${ }^{22}$ The Dow-Jones index is a price-weighted index of 30 blue-chip stocks from U.S. firms that are generally leaders in the industry. The SP500 index is a capitalization-weighted index of 500 stocks that represent all industries that is designed to measure performance of the broad economy.
} 
the emerging economy are taken from the calibration in Arellano (2008): the mean income of the emerging economy is normalized to 1 . The coefficient of risk aversion of the economy is 2 , a standard value considered in the business cycle literature. The free interest rate is set to $1.7 \%$, to match the period under study with the quarterly US interest rate of a bond with a maturity of 5 years. The GDP is assumed to follow a log-normal AR(1) process $\log \left(y_{t}\right)=\rho \log \left(y_{t-1}\right)+\varepsilon^{y}$ with $E\left[\varepsilon^{y}\right]=0$ and $E\left[\varepsilon^{y 2}\right]=\sigma_{y}^{2}$.

The values estimated by Arellano(2008) for the Argentinean economy are $\rho=0.94$ and $\sigma_{y}=0.025$, and the shock is discretized into a 21 state Markov chain using the quadrature based procedure (Hussey and Tauchen (1991)). Following a default there is an asymmetrical function for the output loss that follows:

$$
\phi(y)=\left\{\begin{array}{ll}
\widehat{y} & \text { if } y>\widehat{y} \\
y & \text { if } y \leq \widehat{y}
\end{array}\right\}
$$

with $\widehat{y}=0.969 E(y)$, which in the model with risk neutral investors targets a value of $5.53 \%$ for the average debt service to GDP ratio.

The probability of re-entry to credit markets after defaulting is set at 0.282 , which is consistent with the empirical evidence regarding the exclusion from credit markets of defaulting countries (see Gelos et al. (2002)). The model with risk neutral investors targets a volatility of 1.75 for the trade balance. The discount factor is set a 0.953 which in the model with risk neutral investors targets a annual default probability of $3 \%$.

The parameters for the international investors are set as follows: the representative investor's discount factor is set to 0.98 . If there were no uncertainty, the discount factor of the investors would pin-down the international risk free interest rate (i.e., $\frac{\beta^{L}}{q^{f}}=1$ ); however with uncertainty, in order to have a well defined distribution for the investor's assets, it is necessary to have a value of the discount factor such that $\frac{\beta^{L}}{q^{f}}<1$. The value of $\beta^{L}=0.98$ is the highest value in the range commonly used in business cycle studies of industrialized countries such that the asset distribution of the investors is well defined given an international interest rate of $1.7 \%$. The value of $\beta^{L}$ can be lowered to help the model to generate larger sovereign spreads but at the cost of much more volatility in these spreads.

The representative investor's coefficient of risk aversion is set at 2 ; the criteria to choose this parameter is to generate a mean spread for model that is as close as possible to the mean spread in Argentina for the period of study, which corresponds to 12.67\%. Previous numerical analysis of the model seem to suggest a non-monotonic relation between sovereign spreads and the risk aversion parameter of the investors $\gamma^{L}$ : for low values of risk aversion (i.e, $\gamma^{L} \leq 2$ ) the mean of the simulated sovereign spreads grow with $\gamma^{L}$, while for higher 
values of $\gamma^{L}$ the response of the prices to changes in debt levels is so strong that almost no default is observed at equilibrium.

The representative investor receives a deterministic income of $X=1 \%$ of the emerging economy's mean income in each period. This parameter is set to minimize the joint deviations between the observed long term excess return of the portfolio of an investor in sovereign debt markets and the observed sharpe-ratio of such a portfolio. According to Jostova (2006), if the investment strategy followed by the investor in sovereign debt markets is an active investment strategy (the adjustment in the shares allocated to risky and riskless investments is done based on short term shocks), the annual average sharpe-ratio and the annual average excess return are 0.63 and $19.5 \%$.

The parameter $X$ affects the long term excess return of the portfolio of the investor and the volatility of those returns through its effect on the extent to which the investor is able to borrow from international credit markets. Small values of $X$ imply less possibility of risk free borrowing by investors, and therefore more difficulty for them in smoothing their consumption. As a consequence, investors receive large compensations for making risky investments, and obtain a large excess return on their portfolio. Comparatively, however, the volatility of such a portfolio is even larger. This relatively high volatility of the portfolio translates into small sharpe-ratio for the investors' portfolio. In the data, however, we observe relatively large excess returns and large sharpe-ratios in the portfolio of the investors in sovereign debt markets. In the model there is a tradeoff between excess returns and sharpe-ratios: Low values of $X$ (lower than the one chosen in here) can generate larger excess returns but predict very low sharpe-ratios for the investor's portfolio in comparison to the values observed in the data. On the other hand, high values of $X$ (larger than the considered in here) can match the sharpe-ratio for the investor's portfolio but underestimate the average long term excess return of such portfolio. The numerical simulations of the model in here imply an annual average sharpe-ration and annual excess return of 0.05 and $18.0 \%$.

\subsection{Simulations}

The business cycles statistics of the model are derived as follows: The model is simulated for 20,000 periods. From these 20,000 periods, sub-samples that have economy A staying in the credit market for 74 periods before going into a default are taken to compute the business cycles statistics of the two economies. This process is repeated 5,000 times, and the cycle statistics are the average of the statistics derived from each of these repetitions. 
Table 3: Business Cycle Statistic: The Model and the Data.

\begin{tabular}{||l||c||c|c|c||c|c|c||}
\hline \hline Statistics & Data & RA & RA-4 & RA-D & RN & RN-4 & RN-D \\
\hline \hline mean $\left(r-r^{f}\right)$ & $12.67 \%$ & $5.52 \%$ & $7.99 \%$ & $9.69 \%$ & $4.65 \%$ & $6.68 \%$ & $7.22 \%$ \\
std $\left(r-r^{f}\right)$ & $5.42 \%$ & $3.56 \%$ & $4.54 \%$ & $4.35 \%$ & $2.41 \%$ & $3.59 \%$ & $3.70 \%$ \\
mean $(-(b / y))$ & $53.30 \%$ & $5.19 \%$ & $4.04 \%$ & $3.35 \%$ & $5.92 \%$ & $3.26 \%$ & $2.55 \%$ \\
\hline std $(c) / \operatorname{std}(y)$ & 1.02 & 1.18 & 1.18 & 1.40 & 1.26 & 1.25 & 1.47 \\
std $(t b / y)$ & $1.83 \%$ & $1.03 \%$ & $1.17 \%$ & $1.03 \%$ & $1.48 \%$ & $1.32 \%$ & $1.08 \%$ \\
$\operatorname{corr}(y, c)$ & 0.93 & 0.96 & 0.61 & - & 0.94 & 0.59 & - \\
$\operatorname{corr}\left(y, r-r^{f}\right)$ & -0.60 & -0.38 & -0.49 & - & -0.42 & -0.41 & - \\
corr $(t b / y, y)$ & -0.59 & -0.48 & -0.16 & - & -0.43 & -0.19 & - \\
corr $(W, c)$ & 0.35 & 0.01 & 0.19 & - & 0.00 & 0.00 & - \\
corr $\left(W, r-r^{f}\right)$ & -0.39 & -0.05 & -0.11 & - & 0.00 & 0.00 & - \\
\hline Default Probability & $0.74 \%$ & $1.06 \%$ & - & - & $1.36 \%$ & - & - \\
\hline \hline
\end{tabular}

The results of the simulations are shown in Table 3. The label $R A(R N)$ refers to the results of the simulations with risk averse investors (risk averse investors); $R A-4(R N-4)$ refers to the results of the simulations for the four periods previous to the default episode; $R A-D(R N-D)$ refers to the results of the simulations for the period previous to the default episode.

The simulations presented here show that considering risk averse investors instead of risk neutral investors provides a better match to the risk premium of sovereign bond prices and its volatility as well as to the level of borrowing by emerging economies. Because the risk premium in the asset prices has to be large enough to compensate the investor not only for the probability of default, but also for taking the risk of default, other things equal the model simulated here is able to account for a larger proportion of credit spreads than models with a representative risk neutral investor.

In the data the mean interest rate spread is $12.67 \%$. According to the model here, for the whole period the mean interest rate spread is $5.52 \%$. This value is $1 \%$ larger than the spread of the model with risk neutral investors. Also, for the period before default the spread rises to $9.69 \%$. This value is $2.5 \%$ larger than the value predicted by the model with risk neutral investors. Additionally, the volatility of the spread in the data is $5.42 \%$; in the risk averse model this volatility is $3.56 \%$; while the volatility predicted by the model with risk neutral investors is $2.41 \%$.

It is important to note that this mean spread corresponds to the average for those periods in which the economy is in a repayment state, that is, when the economy is not excluded from financial markets. If the average over all periods is considered, the model generates spreads of $12.37 \%$, while for the model with risk neutral investors this average is $10.25 \%$. 
In the data, the mean debt-to-output ratio is around $53.3 \%$. While this debt-to-output ratio is largely under-predicted by the model, the alternative model does not do a better job in this dimension, and under-predicts this ratio even more for the year previous to the default episode.

The model introduced here also reproduces the counter-cyclical behavior of domestic interest rates. The value of the correlation predicted by both models is lower than the observed value for the data of -0.60 . The numerical solution of the model shows that the correlation between domestic interest rates and output is around -0.38 for the whole period and -0.49 for the year before the default episode. The alternative model (i.e, the model with risk neutral investors) predicts values of -0.42 and -0.41 respectively. While it is not reported in the table, it is worth noting that in the data, during the year previous to the crisis the correlation between output and interest rates is -0.90 ; therefore the model here is consistent with a higher co-movement of the series during periods of economic distress, a result that is not observed for the model of risk neutral investors.

The model also reproduces the counter-cyclical behavior of the trade-balance. The value of the correlation predicted by both models is lower than the observed value for the data -0.59 , but again, the model with risk aversion performs better than the model with risk neutrality. The numerical solution of the model shows that the correlation between tradebalance and output is around -0.48 for the whole period and -0.16 for the year before the default episode. The alternative model (i.e, the model with risk neutral investors) predicts values of -0.43 and -0.19 respectively.

The mean default probability is around $1.06 \%$ for the model with risk averse investors and $1.36 \%$ for the model with risk neutral investors. This rates are equivalent to annual default rates of $4.24 \%$ and $5.44 \%$. These default rates are higher than the default rate found elsewhere. However,even though the results of the current model overestimate the default rate, it is important to highlight that both models, the one with risk averse investors and the one with risk neutral investors, suffer from the same limitation. ${ }^{23}$

The model is also consistent with a few statistics that the previous literature in endogeneous sovereign risk cannot account for: First, the model is able to match the negative

\footnotetext{
${ }^{23}$ The higher default probability and the lower spread for the period before the default episode found in this paper for the same calibration than in Arellano (2008) might be the result of using a different solution method and a different dimension for the economies asset position. In the current paper, the emerging economy's asset grid has 600 positions while in Arellano (2008) this grid has 200 positions. As discussed in Hatchondo and Martinez (2006) models of endogenous sovereign risk are somewhat sensitive to the solution method employed and how sparse is the grid for the asset position of the economy.
} 
correlation between a measure of the investors' performance, the SP500, and Argentina's interest spread. In the data, the correlation between these measures is -0.39 . The model generates a value for this correlation of -0.05 for the whole period, with the value of the correlation rising to -0.11 during the year previous to the default.

Second, in the data, Argentina's consumption and the SP500 are positively correlated at 0.35 ; in the model the correlation between investors wealth and consumption is 0.01 for the whole period, but the value raises to 0.19 for the year previous to the default episode.

Where the two previous correlations predicted by the model are relatively low in comparison to the ones observed in the data, the model might be improved by making investors subject to some kind of stochastic shocks that represent, for example, changes in international interest rates or investors' own external resources. Including this additional source of uncertainty in the model could also generate larger spreads, which would also be more in line with the observed data.

\section{Conclusion}

This paper presents a stochastic dynamic general equilibrium model of default risk that endogenizes the role of external factors in the determination of small open economies' incentives to default, sovereign bond prices, capital flows and default episodes.

The empirical literature on international finance presents evidence that points to a very relevant role for investors' characteristics - risk aversion and wealth - in the determination of sovereign credit spreads and capital flows to emerging economies. The model in this paper is the first model with endogenous default risk that can account for these empirical findings. By relaxing the assumption of risk neutrality on the side of international investors and assuming that the preferences of these agents exhibit decreasing absolute risk aversion, this model generates a link between international investors' characteristics and emerging economies' sovereign credit markets.

Therefore, the contribution of the paper is twofold. First, the paper qualitatively and quantitatively characterizes the role of investors' characteristics in the determination of small open economies' optimal plans when international credit contracts cannot be enforced. Second, the paper presents a theoretical framework that is extended in a companion paper (Lizarazo (2010)) to a multi-country setup to study endogenous financial links across countries with common investors. This extension can explain endogenously the occurrence of contagion in sovereign debt markets of emerging economies. 
Regarding the role of investors' characteristics, the analytical results of this model establish that default risk increases with investors' risk aversion and decreases with investors' wealth. Investors' characteristics have the opposite effect on capital flows. Capital flows decrease with investors' risk aversion and increase with investors' wealth. As a consequence, credit limits are tighter when investors are more risk averse or less wealthy.

Quantitatively, the model developed here outperforms previous models of endogenous default risk in several ways. Compared to risk-neutral models using the same parameterizations, the current model performs better at explaining sovereign yield spreads levels and equilibrium debt levels. In comparison to those models with risk neutral investors, the present model supports a combination of higher levels of debt at equilibrium and higher and more volatile spreads. The model is also able to replicate the counter-cyclical behavior of domestic interest rates and the trade balance. The model is also consistent with the observed positive correlation between measures of investors performance and interest rate spreads: this model exhibits the expected negative correlation between investors' wealth and sovereign spreads.

While the model improves on explaining the behavior of prices and quantities with respect to models of the same type that do not consider investors' characteristics, the model is not without shortcomings. For example, the maximum level of debt supported at equilibrium is only around $5.1 \%$ of the output, which is much lower than the $53.3 \%$ average reached by Argentina at the verge of default reported in Reinhart et al.(2003). Also, from a computational perspective, the inclusion of an additional state variable (the level of wealth of the investors) makes solving this problem much more intensive than the simpler model.

Nonetheless the model presented here opens the door to an important economic issuethat the creditworthiness of a country can be partially explained by factors other than the country's own fundamentals. This more general framework can shed light on a multitude of policy questions: the optimal degree of diversification of international portfolios; the appropriateness of capital controls to exclude volatile short-term flows; the role of the IMF in preventing crises; the impact of term-structure on debt markets; and the transmission of crises from debt markets to equity markets. While these questions remain to be explored, a clear message emerges from the current analysis: The consideration of risk averse investors goes a long way toward explaining sovereign bond spreads and the behavior of borrowers and investors in emerging markets. 


\section{References}

[1] Aiyagari, R., (1994). "Uninsured Idiosyncratic Risk and Aggregate Saving." Quarterly Journal Of Economics 109(3), 600-684, 1994.

[2] Aguiar, M., and Gopinath, G., (2006). "Defaultable Debt, Interest Rates and the Current Account." Journal of International Economics 69, 64-83, 2006.

[3] Arellano, C., (2008). "Default Risk and Income Fluctuations in Emerging Economies." American Economic Review 98, 670-712, 2008.

[4] Arora, V., and Cerisola, M., (2001). "How Does US Monetary Policy Influence Sovereign Spreads in Emerging Markets?." IMF Staff Papers Vol 48, No 3, International Monetary Fund.

[5] Bai, Y., and Zhang, J.,(2006). "Financial Integration and International Risk Sharing." Working Paper Michigan University, 2006.

[6] Baig, T., and Goldfajn, I.,(1998). "Financial Market Contagion in the Asian Crisis." IMF Working Paper WP/98/155, November 1998.

[7] Baig, T., and Goldfajn, I.,(2000). "The Russian default and the Contagion to Brazil." IMF Working Paper WP/00/160, October 2000.

[8] Bekaert, G., Harvey, C., and Lumsdaine, R., (2002). "Thedynamics of emerging market equity flows." Journal of International Money and Finance 21(3), 295-350, 2002.

[9] Broner, F., Lorenzoni, G., and Schmulker, S., (2005). "Why do emerging economies borrow short term?." Working Paper MIT, 2005.

[10] Cantor, R., and Packer, F, (1996). "Determinants and Impact of Sovereign Credit Ratings." Economic Policy Review October, 1996. Federal Reserve Bank of New York.

[11] Chatterjee, S., Corbae, D., Nakajima, M., and Rios-Rull, J., (2007). "A Quantitative Theory of Unsecured Consumer Credit with Risk of Default." Econometrica 75, 15251589, 2007.

[12] Cline, W., and Barnes, K., (1997). "Spreads and Risk in Emerging Market Lending." Working Paper 97-1, December 1997. Institute of International Finance.

[13] Cuadra, G., and Sapriza, H., (2008). "Sovereign default, interest rates and political uncertainty in emerging markets." Journal of International Economics , 2008 (forthcoming). 
[14] Cunningham, A., Dixon, L., and Hayes, S., (2001). "Analyzing Yield Spreads on Emerging Market Sovereign Bonds." Financial Stability Review, December 2001.

[15] Eaton, J., and Gersovitz, M.,(1981). "Debt with Potential Repudiation: Theoretical and Empirical Analysis." Review of Economic Studies Vol XLVIII, 289-309.

[16] Eichengreen, B., and Mody, A., (2002). "Interest Rates in the North and Capital Flows to the South: Is There a Missing Link? "International Finance Vol 1, Issue 1, 35-57, 2002 .

[17] Ferruci, G., Herzberg, V., Soussa, F., Taylor, A., (2004). "Understanding Capital Flows to Emerging Market Economies." Financial Stability Review: June 2004.

[18] FitzGerald, V., and Krolzig, D., (2003). "Modeling the Demand for Emerging Market Assets." Working Paper, April (2003).

[19] Forbes, K., and Rigobon, R., (1999). "No contagion only Interdependence: Measuring Stock Market Comovements ". NBER Working Paper 7267, July 1999

[20] Gelos, G., Sahay R., and Sandleris, G., (2004). "Sovereign Borrowing in Developing Countries: What Determines Market Access?." Working Paper, 04/221, IMF, 2004.

[21] Goldberg, L., (2006). "The International Exposure of US Banks: Europe and Latin American Compare ." NBER Working Paper, 11365, May 2005.

[22] Hatchondo, J., and Martinez, L., (2006) "Computing Business Cycles in Emerging Economy Models " The Federal Reserve Bank of Richmond Working Paper, 06-11, (2006).

[23] Hatchondo, J., Martinez, L. and Sapriza H., (2008) "Heterogeneous Borrowers in Quantitative Models of Sovereign Default "International Economic Review (forthcoming), (2008).

[24] Hernandez, L., Mellado, P., and Valdes, R., (2001). "Determinants of Private capital flows in the 1970s and 1990s: Is there evidence of Contagion?." IMF Working Paper WP/01/64, May 2001.

[25] Hernandez, L., and Valdes, R., (2001). "What drives Contagion: Trade, Neighborhood, or Financial links " IMF Working Paper WP/01/29, March 2001.

[26] Jostova, G., (2006). "Predictability in Emerging Sovereign Debt Markets "Journal of Business vol. 79, no. 2. 
[27] Kamin, S. and von Kleist, K., (1999). "The Evolution and Determinants of Emerging Market Credit Spreads in the 1990s." Working Paper (1999). Bank for International Settlements and Federal Reserve Board.

[28] Kaminsky, G., and Reinhart, C., (1998). "Financial Crises in Asia and Latin America: Then and Now." American Economic Review Vol 88, Issue 2, Papers and Proceedings of the Hundred and Tenth Annual Meeting of the American Economic Association, May 1998, 444-448.

[29] Kaminsky, G., and Reinhart, C., (2000). "On crises contagion and confusion." Journal of International Economics 51(1), 145-168, 2000.

[30] Kamisnky, G., Lyons, R., and Schmukler, S., (2001). "Mutual Fund Investment In emerging Markets: An Overview." The World Bank Economic Review, Vol 15, No 2 315-340, 2001.

[31] Kletzer, K. and Wright, B.,(2000) "Sovereign Debt as Intertemporal Barter" American Economic Review 90(3), 621-639, 2000.

[32] Lizarazo, S., (2010) "Contagion of Financial Crises in Sovereign Debt Markets." Working Paper ITAM, January 2010.

[33] Mody, A., and Taylor, M., (2003). "The High Yield Spread as a Predictor of Real Economic Activity: Evidence of a Financial Accelerator for the United States." IMF Staff papers 50(3), 373-402, 2003.

[34] Neumeyer, P., and Perri, F., (2005). "Business Cycles in Emerging Economies: The Role of Interest Rates." Journal of Monetary Economics 52/2, 345-380, March 2005.

[35] Paasche, B., and Zin, S., (2001). "Competition and Intervention in Sovereign Debt Markets." NBER Working Paper 8679, December 2001.

[36] Reinhart, C., (2002). "Default, Currency Crises and Sovereign Credit Ratings." NBER Working Paper 8738, January 2002.

[37] Reinhart, C., Rogoff, K., and Savastano, M., (2003). "Debt Intolerance." NBER Working Paper 9908, August 2003.

[38] Uribe, M., and Yue, V., (2006). "Country Spreads and Emerging Countries: Who Drives Whom?." Journal of International Economics 69, 6-36, 2006. 
[39] Valdes, R., (1996). "Emerging Markets Contagion: Evidence and theory." . Banco Central de Chile. Documentos de Trabajo del Banco Central.

[40] Van Rijckeghem, C. and Weder, B., (2001). "Sources of Contagion: Finance or Trade?." Journal of International Economics54(2), 293-308, 2001

[41] Warther, V., (1995). "Aggregate Mutual Funds Flows and Security Returns." Journal of Financial Economics, 39, 209-235

[42] Westphalen, M., (2001). "The Determinants of Sovereign Bond Spreads Changes." Working Paper, Universite de Lausanne, and Fame, November (2001).

[43] Wright, M., (2002). "Reputations and Sovereign Debt." Working Paper, September 2002 .

[44] Yue, V., (2006). "Sovereign Default and Debt Renegotiation." Working Paper, New York University, November 2006. 


\section{Appendix 1}

\section{Proofs}

The proofs that follow assume the extreme case of permanent exclusion of credit markets after default by the emerging economy. This assumption simplifies the proofs because in this case the value of the value function of default is independent of the investor's degree of risk aversion and wealth level. However the results can be generalized to the case of temporary exclusion using the following argument: In the more general case of temporary exclusion after a default, the value of the value function of default depends on the risk aversion and the wealth of the investors but with a discount: the future periods in which the economy might re-enter the credit market are discounted by the economy's discount factor $\beta$ and by the probability of re-entering credit markets $\tau$, both of which are lower than 1 . This discounting of the future implies that in response to changes in the coefficient of risk aversion or changes in the level of wealth of the investors, the value function of repayment must respond more strongly than the value function of default. Therefore the results of these proofs will also hold for the more general case using the argument of continuity with respect to the probability of re-entering credit markets that can vary between 0 and 1 .

In what follows is important to remember the assumption that the representative investor does not go short in the emerging economy assets (whenever the emerging economy is saving the investor receives the savings and invest them completely in T-Bills). This assumption implies that in equilibrium $\theta_{j}^{\prime} \geq 0$ and whenever $\theta_{j}^{\prime}>0$ then $b_{j}^{\prime}<0$. Then the more negative is $b_{j}^{\prime}$ the more an economy $j$ is able to borrow from the investors.

Proposition 2 For any state of the world s, the emerging economies' incentives to default are stronger in a world with a more risk averse representative investor than in a world with a less risk averse representative investor.

Proof. The investor's value function can be written as

$$
V^{L}=E \sum_{t=\tau}^{\infty} \beta^{t-\tau} v\left(X+\theta_{t}^{T B}-q^{f} \theta_{t+1}^{T B}+d_{t}\left[\theta_{t}-q_{t} \theta_{t+1}\right]\right) .
$$

Considering the case in which the economy has not defaulted in the current period (otherwise the investor will not invest in this economy in this period) and assuming an interior solution for the allocation to the emerging economy's asset

$$
\phi\left(\theta^{\prime}\right)=E\left\{-q v_{c}\left(c_{L}\left(\theta^{\prime}\right)\right)+\beta v_{c}\left(c_{L}^{\prime}\left(\theta^{\prime}\right)\right) d^{\prime}\right\}=0
$$


If the periodic utility of the international investor is of the CRRA type and $\gamma_{1}^{L}<\gamma_{2}^{L}$, then there exists a concave function $\psi(\cdot)$ such that $v_{2}\left(c ; \gamma_{2}^{L}\right)=\psi\left(v_{1}\left(c ; \gamma_{2}^{L}\right)\right)$. If $\theta_{1}^{\prime}$ is the optimal allocation when $\gamma^{L}=\gamma_{1}^{L}$, and $\theta_{2}^{\prime}$ is the optimal allocation when $\gamma^{L}=\gamma_{2}^{L}$ then it holds that

$$
\begin{aligned}
& \phi_{1}\left(\theta_{1}^{\prime}\right)=E\left\{-q v_{1, c}\left(c_{L}\left(\theta_{1}^{\prime}\right)\right)+\beta v_{1, c}\left(c_{L}^{\prime}\left(\theta_{1}^{\prime}\right)\right) d^{\prime}\right\}=0 . \\
& \phi_{2}\left(\theta_{2}^{\prime}\right)=E\left\{-q v_{2, c}\left(c_{L}\left(\theta_{2}^{\prime}\right)\right)+\beta v_{2, c}\left(c_{L}^{\prime}\left(\theta_{2}^{\prime}\right)\right) d^{\prime}\right\}=0 .
\end{aligned}
$$

Using $v_{2}\left(c ; \gamma_{2}^{L}\right)=\psi\left(v_{1}\left(c ; \gamma_{2}^{L}\right)\right)$ it is possible to define

$$
\phi_{2}\left(\theta_{1}^{\prime}\right)=E \psi^{\prime}\left[v_{1}\left(\theta_{1}^{\prime}\right)\right]\left\{-q v_{1, c}\left(c_{L}\left(\theta_{1}^{\prime}\right)\right)+\beta v_{1, c}\left(c_{L}^{\prime}\left(\theta_{1}^{\prime}\right)\right) d^{\prime}\right\}<0 .
$$

The last inequality comes from the fact that $\psi^{\prime}(\cdot)$ is positive and decreasing. The inclusion of this function in the previous equation implies that $\phi_{2}\left(\theta_{1}^{\prime}\right)$ is lower than $\phi_{2}\left(\theta_{2}^{\prime}\right)$ because $\psi^{\prime}(\cdot)$ gives little weight to the realizations of $d^{\prime}=1$, and high weight to the realizations of $d^{\prime}=0$. Therefore

$$
\phi_{2}\left(\theta_{2}^{\prime}\right)>\phi_{2}\left(\theta_{1}^{\prime}\right) .
$$

The concavity of $V^{L}(\cdot)$ implies that given $q$ and the risk of default (represented by the expected realizations of $\left.d^{\prime}\right) \phi\left(\theta^{\prime}\right)$ is a decreasing function, and as consequence

$$
\theta_{2}^{\prime}<\theta_{1}^{\prime}
$$

which in equilibrium implies $b_{2}^{\prime}>b_{1}^{\prime}$.

Then for any state of the world $s$ and taking as given $q$ and the risk of default $(\delta)$, a higher degree of risk aversion of the investor would result in this agent allocating a lower proportion of her portfolio to the economy's sovereign bonds. Therefore, when the investor is less risk averse there are financial contracts that are available to the emerging economy that are not available when the investor is more risk averse. Consequently, given $q$ and $\delta$,

$$
V_{1}^{C}\left(s ; \gamma_{1}^{L}\right) \geq V_{2}^{C}\left(s ; \gamma_{2}^{L}\right)
$$

Because the utility of autarky for the emerging economy does not depend on the investor's risk aversion, it is clear that if for some state of the world, $s$, default is optimal when $\gamma^{L}=\gamma_{1}^{L}$, then for the same state of the world default would be optimal when $\gamma^{L}=\gamma_{2}^{L}$. Additionally, because incentives to default would be higher whenever $\gamma^{L}=\gamma_{2}^{L}$, than when $\gamma^{L}=\gamma_{1}^{L}$ at equilibrium $\delta\left(s, b^{\prime} ; \gamma_{2}^{L}\right)>\delta\left(s, b^{\prime} ; \gamma_{1}^{L}\right)$, and therefore $q\left(s, b^{\prime} ; \gamma_{2}^{L}\right)<q\left(s, b^{\prime} ; \gamma_{1}^{L}\right)$. Then, unambiguously for all states of the world, the emerging economy faces stronger incentives to default when the investor is more risk averse. 
Proposition 3 Default sets are shrinking in assets of the representative investor. For all $W_{1}<W_{2}$, if default is optimal for $b$ in some states $y$, given $W_{2}$, then default will be optimal for $b$ for the same states $y$, given $W_{1}$. Therefore $D\left(b \mid W_{2}\right) \subseteq D\left(b \mid W_{1}\right)$

Proof. Proof: From Equation (9), if $W_{1}<W_{2}$, then for any given $q$ and taking as given the level of default risk,

$$
b_{1}^{\prime}>b_{2}^{\prime}
$$

This inequality holds because decreasing absolute risk aversion implies that

$$
v\left(X+W_{1}-q^{f} \theta_{t+1}^{T B}-d_{t} q_{t} \theta_{t+1}\right)
$$

is a concave transformation of

$$
v\left(X+W_{2}-q^{f} \theta_{t+1}^{T B}-d_{t} q_{t} \theta_{t+1}\right)
$$

so if $\theta_{1}^{\prime}$ is the optimal allocation when $W=W_{1}$, and $\theta_{2}^{\prime}$ is the optimal allocation when $W=W_{2}$, defining

$$
\begin{aligned}
& v_{1}\left(\theta_{1, t+1}\right)=v\left(X+W_{1}-q^{f} \theta_{t+1}^{T B}-d_{t} q_{t} \theta_{1, t+1}\right) \\
& v_{2}\left(\theta_{2, t+1}\right)=v\left(X+W_{2}-q^{f} \theta_{t+1}^{T B}-d_{t} q_{t} \theta_{2, t+1}\right)
\end{aligned}
$$

then

$$
\begin{aligned}
& \phi_{1}\left(\theta_{1}^{\prime}\right)=E\left\{-q v_{1, c}\left(c_{L}\left(\theta_{1}^{\prime}\right)\right)+\beta v_{1, c}\left(c_{L}^{\prime}\left(\theta_{1}^{\prime}\right)\right) d^{\prime}\right\}=0 \\
& \phi_{2}\left(\theta_{2}^{\prime}\right)=E\left\{-q v_{2, c}\left(c_{L}\left(\theta_{2}^{\prime}\right)\right)+\beta v_{2, c}\left(c_{L}^{\prime}\left(\theta_{2}^{\prime}\right)\right) d^{\prime}\right\}=0
\end{aligned}
$$

and because $v_{1}\left(\theta_{t+1}\right)=\psi\left(v_{2}\left(\theta_{t+1}\right)\right)$

$$
\phi_{1}\left(\theta_{2}^{\prime}\right)=E \psi^{\prime}\left[v_{2}\left(\theta_{2}^{\prime}\right)\right]\left\{-q v_{2, c}\left(c_{L}\left(\theta_{2}^{\prime}\right)\right)+\beta v_{2, c}\left(c_{L}^{\prime}\left(\theta_{2}^{\prime}\right)\right) d^{\prime}\right\}<0 .
$$

The inequality comes from the fact that $\psi^{\prime}(\cdot)$ is positive and decreasing. The inclusion of this function in the previous equation implies that $\phi_{1}\left(\theta_{2}^{\prime}\right)$ is lower than $\phi_{1}\left(\theta_{1}^{\prime}\right)$ because $\psi^{\prime}(\cdot)$ gives little weight to realizations of $d^{\prime}=1$, and high weight to realizations of $d^{\prime}=0$. Therefore

$$
\phi_{1}\left(\theta_{2}^{\prime}\right)<\phi_{1}\left(\theta_{1}^{\prime}\right) .
$$

The concavity of $V^{L}(\cdot)$ implies that given $q$ and the risk of default (represented by the expected realizations of $\left.d^{\prime}\right), \phi\left(\theta^{\prime}\right)$ is a decreasing function, and as consequence

$$
\theta_{2}^{\prime}>\theta_{1}^{\prime}
$$


which in equilibrium implies $b_{2}^{\prime}<b_{1}^{\prime}$.

Then for any state of the world $s$ and taking as given $q$ and the risk of default $(\delta)$, a lower level of investor's wealth would result in this agent allocating a lower proportion of her portfolio to the economy's sovereign bonds. Therefore, when the investor is more wealthy there are financial contracts that are available to the emerging economy that are not available when the investor is less wealthy. Consequently, given $q$ and $\delta$,

$$
V_{1}^{C}\left(s ; W_{2}\right) \geq V_{2}^{C}\left(s ; W_{1}\right) .
$$

Because the utility of autarky for the emerging economy does not depend on the investor's wealth, it is clear that if for some state of the world, $s$, default is optimal when $W=W_{2}$, then for the same state of the world default would be optimal when $W=W_{1}$. Additionally, because incentives to default would be higher whenever $W=W_{1}$, than when $W=W_{2}$ at equilibrium $\delta\left(s, b^{\prime} ; W_{1}\right)>\delta\left(s, b^{\prime} ; W_{2}\right)$, and therefore $q\left(s, b^{\prime} ; W_{1}\right)<q\left(s, b^{\prime} ; W_{2}^{L}\right)$. Then, unambiguously for all states of the world, the emerging economy faces stronger incentives to default when the investor is less wealthy. 